\title{
Les récepteurs des entérotoxines bactériennes
}

\author{
Élodie Rousset, J. Daniel DubreuIL* \\ Groupe de recherche sur les maladies infectieuses du porc (GREMIP), Département de pathologie \\ et microbiologie, Faculté de médecine vétérinaire, Université de Montréal, 3200 rue Sicotte, \\ Saint-Hyacinthe, Québec, Canada, J2S 7C6
}

(Reçu le 31 janvier 2000, accepté le 27 avril 2000)

\begin{abstract}
Bacterial enterotoxin receptors. Enteric bacterial toxins display a great diversity in their structure, molecular weight and mechanism of action. The interaction of enterotoxins with the intestinal mucosa either leads to a direct effect on the cell membrane or an effect on signal transduction within eukaryotic cells. However, before a toxin can affect a cell, it must after its secretion by a microorganism, recognise and bind to a specific surface molecule, its receptor. Membrane receptors of bacterial enterotoxins have been identified as protein, glycoprotein or glycolipid in nature. The chemical nature of the molecules acting as receptors is crucial and during evolution they have been carefully selected. Some toxins, after their interaction with a receptor molecule, will transduce a signal across the cell membrane while remaining at the cell surface. Other toxins, after this initial binding step with a receptor, will be internalised. Others can form pores leading to leakage of cellular components and cell lysis. Receptors that have been identified often comprise a saccharidic chain that is directly involved in the recognition and binding of the toxin. Today, models explaining toxin-receptor interactions are more complex, including multistep events. This review summarises the knowledge of the interactions between bacterial toxins and membrane receptors present on intestinal mucosa.
\end{abstract}

receptor / intestine / enterotoxin / binding epitope / glycosphingolipid

Résumé - Les toxines bactériennes entériques présentent une grande diversité autant dans leur structure que dans leur poids moléculaire et leur mécanisme d'action. L'interaction des entérotoxines avec la muqueuse intestinale conduit soit à un effet direct sur la paroi cellulaire de la cellule hôte, soit à un dérèglement des voies de signalisation de celle-ci. Toutefois, avant même d'affecter la cellule cible, la toxine sécrétée par le micro-organisme devra reconnaître et s'attacher à une molécule présente à la surface cellulaire, son récepteur. Les récepteurs membranaires des entérotoxines bactériennes peuvent être de nature protéique, glycoprotéique ou glycolipidique. La nature chimique de ces récepteurs, sur laquelle repose la spécificité, est primordiale et au cours de l'évolution ceuxci ont été soigneusement sélectionnés. Certaines toxines, une fois en contact avec leur récepteur, envoient un signal à l'intérieur de la cellule tout en demeurant à la surface alors que d'autres toxines sont internalisées. Enfin, certaines toxines bactériennes peuvent former des pores dans la membrane

* Correspondance et tirés-à-part

Tél. : (1) (450) 7738521 poste 8433 ; fax : (1) (450) 7788108 ; e-mail : daniel.dubreuil@ umontreal.ca 
des cellules cibles conduisant à la perte du contenu cellulaire et à la lyse. Les récepteurs identifiés jusqu'ici comportent très souvent une partie saccharidique qui s'avère régir la reconnaissance et l'attachement des toxines. Aujourd'hui, certains modèles d'interaction entre les entérotoxines (ligands) et leurs récepteurs rendent compte d'un attachement en plusieurs étapes. Une synthèse des connaissances des interactions entre les toxines bactériennes et les récepteurs membranaires de la muqueuse intestinale fait l'objet de cette revue.

\section{récepteur / intestin / entérotoxine / épitope d'attachement / glycosphingolipide}

Plan

1. Introduction.... 414

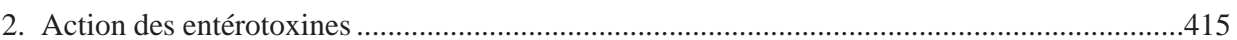

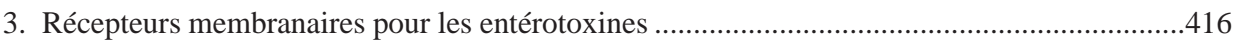

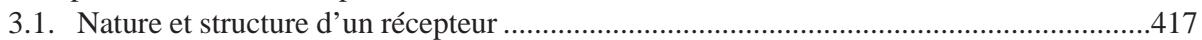

3.2. Reconnaissance et attachement à un glycoconjugué .....................................................419

3.2.1. Caractéristiques des glycoconjugués présents à la surface des cellules ...............419

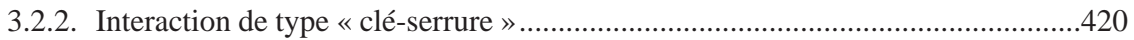

3.2.3. Reconnaissance de séquences internes - Isorécepteurs .....................................421

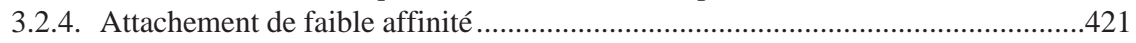

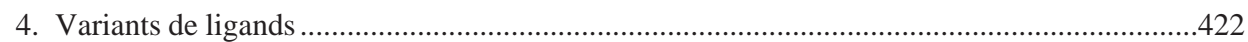

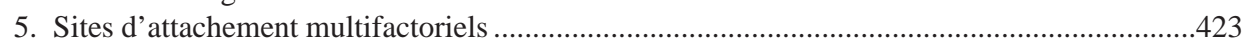

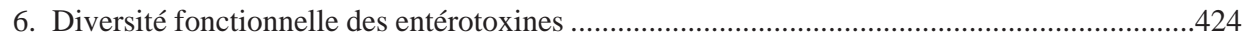

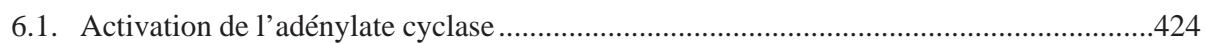

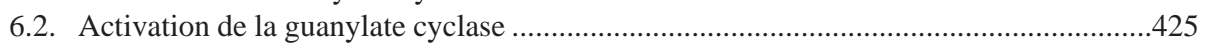

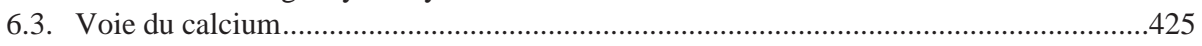

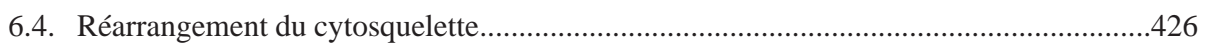

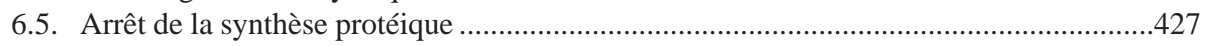

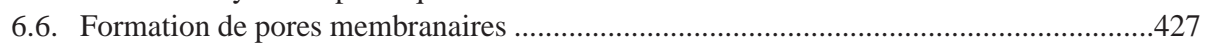

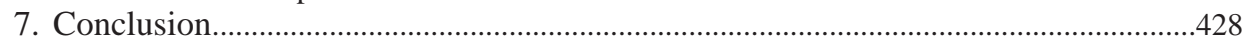

\section{INTRODUCTION}

Les toxines entériques sont capables, en très faible quantité, de déclencher une sécrétion de fluide dans la lumière intestinale provoquant ainsi une diarrhée. La connaissance des mécanismes d'action utilisés par les diverses entérotoxines bactériennes connues est essentielle à la compréhension de leurs effets toxiques. Dans cette revue, nous nous sommes limités à la première étape, précédant le processus sécrétoire moléculaire d'une entérotoxine, à savoir l'attachement à une molécule dite « récepteur » localisée dans la membrane plasmique de la cellule cible.
Dans les cellules eucaryotes, les récepteurs jouent un rôle primordial dans la communication de cellule à cellule et dans la transduction spécifique d'un signal. Au cours de l'évolution, de nombreux microorganismes pathogènes ont sélectionné des sites d'attachement spécifiques pour leur colonisation et/ou invasion. Une fois le micro-organisme établi, les toxines produites pourront être dirigées vers les cellules cibles de l'hôte [132]. Il est accepté aujourd'hui que l'attachement à la cellule hôte est l'étape initiale d'un processus d'infection. Les particularités biochimiques et structurales des molécules agissant comme récepteurs pour les toxines seront discutées. 
Une fois la reconnaissance du récepteur et son attachement par l'entérotoxine effectués, une cascade d'évènements variant d'une toxine à l'autre est déclenchée conduisant ultérieurement à un déséquilibre des fluides et électrolytes de l'hôte. Les nombreux moyens utilisés par les toxines bactériennes entériques pour provoquer la diarrhée chez l'hôte seront exposés.

\section{ACTION DES ENTÉROTOXINES}

L'épithélium intestinal représente la plus étendue des interfaces entre l'environnement externe et le milieu interne de l'hôte. C'est une structure complexe contenant de nombreux types cellulaires (Fig. 1). Les villosités de la muqueuse font saillie dans la lumière de l'intestin. Chaque villosité comprend un axe central de tissu conjonctif et une couche de cellules épithéliales en colonne appuyées sur une membrane basale.
Les cellules épithéliales sont générées à la base des villosités et se différencient lorsqu'elles migrent jusqu'au sommet des villosités, où elles sont ensuite éliminées par desquamation. Les microvillosités des entérocytes se projettent du pôle apical des cellules vers la lumière pour former ensemble une bordure en brosse absorbante. Elles sont constituées par des plissements membranaires et offrent une grande surface d'échange. En fait, le mécanisme sécrétoire est peu sollicité dans les conditions usuelles, mais est une des composantes fondamentales des diarrhées les plus sévères. Les entérocytes possèdent, dans leur membrane apicale, des canaux protéiques qui ont des propriétés spécifiques dans le transport des ions. Pour causer une diarrhée, un pathogène entérique doit interférer avec les fonctions sécrétoires des cellules intestinales de façon directe ou indirecte. Les effets directs sont généralement attribués aux entérotoxines. Une activité sécrétoire est déclen-

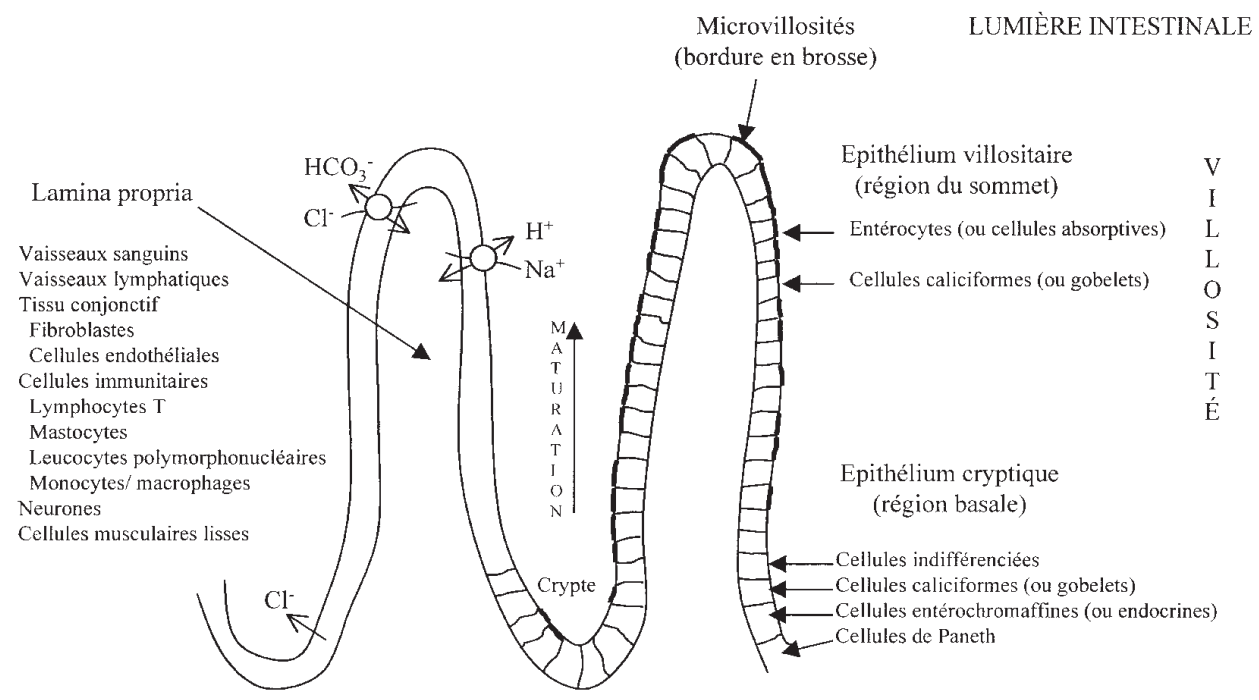

Figure 1. Coupe longitudinale de villosités de la muqueuse intestinale montrant les composants cellulaires et l'organisation histologique. Les transports d'ions des cellules épithéliales sont représentés : l'absorption du sodium $\mathrm{Na}^{+}$, la sécrétion de chlore $\mathrm{Cl}^{-}$et la sécrétion de bicarbonate $\mathrm{HCO}_{3}^{-}$. 
chée dans certaines portions de l'intestin, suite à une diminution de la réabsorption du sodium et à une augmentation de la sécrétion du chlore ou de bicarbonate. Cette accumulation d'électrolytes dans la lumière intestinale entraîne, par phénomène d'osmose, une perte d'eau par les cellules épithéliales [84]. Plusieurs facteurs de l'hôte, tels que les neurohormones libérées par les cellules entérochromaffines, les neurotransmetteurs du système nerveux entérique, les cellules musculaires intestinales, les cytokines libérées par les cellules épithéliales ou les cellules immunitaires de la sous-muqueuse, peuvent contribuer à la sécrétion intestinale et donc indirectement à l'action des entérotoxines [132].

Les entérotoxines bactériennes protéiques sont généralement classées selon leurs caractéristiques biochimiques et structurales d'une part : masse moléculaire, nombre de sousunités, sensibilité à la chaleur ou aux enzymes et, d'autre part, selon leurs modes d'action ou leurs types d'activités biologiques. Sur la base de cette dernière classification, ces molécules peuvent être distinguées en deux groupes : les entérotoxines cytotoniques et les entérotoxines cytotoxiques [38, 52, 96, 97]. Les entérotoxines cytotoniques affectent les cellules épithéliales intestinales pour en altérer directement les fonctions sécrétoires. Le caractère principal de ces entérotoxines réside dans leur pouvoir d'induire une réponse sécrétoire en anses intestinales ligaturées dans un modèle animal [8]. La toxine du choléra et les entérotoxines produites par les Escherichia coli enterotoxinogènes (ETEC) provoquent ce type de diarrhée non-inflammatoire rapide et déshydratante [113]. En revanche, les entérotoxines cytotoxiques, peu ou pas actives dans les anses intestinales ligaturées, agissent sur l'épithélium intestinal en y provoquant des dommages histologiques importants. Les représentants des entérotoxines cytotoxiques les plus connus sont les vérotoxines VTI, VTII (ou toxine «Shiga-like», Stx1 et Stx2) des E. coli, la toxine Shiga ou vérotoxine de
Shigella, la toxine A de Clostridium difficile et l'entérotoxine CPE de Clostridium perfringens. Chez l'homme, le rôle de Stx1 et Stx2 n'a pas été clairement établi [99].

Il n'est cependant pas toujours évident de grouper chaque toxine entérique dans l'un de ces deux types d'activité. Par ailleurs, l'augmentation de la réponse sécrétoire à une toxine peut aussi dépendre, non seulement de facteurs de l'hôte, mais aussi de plusieurs facteurs bactériens, tels que les facteurs de colonisation intestinale et/ou les facteurs d'invasion de l'épithélium. La synthèse d'une protéine de virulence peut également avoir un effet sur un autre facteur de virulence. Par exemple, la neuraminidase produite par Vibrio cholerae catalyse la conversion de longs gangliosides en monosialogangliosides GM1. GM1 étant le récepteur de la toxine du choléra (CT), cela permet d'augmenter l'attachement de la toxine aux cellules et donc, la réponse sécrétoire provoquée par CT [49].

\section{RÉCEPTEURS MEMBRANAIRES POUR LES ENTÉROTOXINES}

Les neurotransmetteurs, les hormones, incluant les facteurs de croissance, et les messagers du système immunitaire, tels que les cytokines, exercent leurs actions sur les cellules cibles par l'intermédiaire de récepteurs membranaires. Seules les hormones liposolubles et de petite taille traversent directement la membrane plasmique. Classiquement, les sites d'attachement des récepteurs sont occupés par un agoniste, c'est-àdire la molécule qui va induire une réponse à partir du récepteur. Le processus utilisé, appelé «transduction du signal », implique deux étapes consécutives caractéristiques. Le récepteur capte le messager physiologique extracellulaire, puis communique l'information au compartiment intracellulaire. Le signal intracellulaire va, à son tour, propager la réponse pour activer la sécrétion, le métabolisme, la contraction, la croissance ou d'autres effets de la régulation cellulaire. 
Les cellules intestinales possèdent quatre voies intracellulaires principales pour réguler le transport transépithélial des ions : les voies dépendantes du $\mathrm{Ca}^{2+}$, le GMPc, l'AMPc et le réarrangement du cytosquelette $[37,84,160]$. Une toxine entérique peut donc utiliser au moins l'un de ces régulateurs du transport des électrolytes des cellules intestinales pour induire une sécrétion ou d'autres voies pour exercer des effets physiologiques propres aux cytotoxines.

Les connaissances sur les mécanismes d'action de chaque toxine varient considérablement. Pour quelques cas seulement, le mécanisme moléculaire est compris en détail. Les toxines bactériennes sont généralement divisées en deux groupes en fonction de leur site d'action : celles qui agissent sur une cible intracellulaire et celles qui agissent sur la membrane plasmique [34, $50,96,105]$. Certaines toxines agissent sur un récepteur stimulant la libération ou la production d'un second messager intracellulaire (comme le GMPc ou le calcium), qui active souvent une kinase. D' autres, agissent sur la cellule via une activité enzymatique intrinsèque; ce sont le plus souvent des toxines de type A-B. La sous-unité B («Binding ») permet la liaison de la toxine au récepteur de la cellule eucaryote, alors que la sous-unité A («Activity »), qui possède une fonction enzymatique spécifique agissant à l'intérieur de la cellule, est transloquée à travers la membrane cellulaire eucaryote vers son substrat dans le cytosol. Enfin, des toxines s'insèrent directement dans la membrane plasmique, créant un pore de plus ou moins grande taille. La réponse des entérotoxines dites cytotoniques implique souvent l'activation d'un système cyclasique (adénylate ou guanylate cyclase). Le mécanisme d'action des entérotoxines dites cytotoxiques est généralement moins connu, mais est corrélé dans la plupart des cas à une perturbation des grandes fonctions cellulaires, comme la synthèse protéique ou la perméabilité aux ions, aux acides aminés ou au glucose.
Comme pour les hormones, la sélectivité de la réponse aux toxines dépend en général de récepteurs particuliers à la surface des cellules. Dans le processus d'action d'une toxine, l'attachement à la surface des cellules animales de l'hôte est reconnu comme une étape caractéristique essentielle à comprendre pour déterminer comment les fonctions intestinales sont spécifiquement altérées pour provoquer une diarrhée. L'attachement des entérotoxines constitue en l'occurrence, l'étape initiale de la pathologie et, en conséquence, les récepteurs membranaires des entérotoxines jouent un rôle aussi important que les toxines ellesmêmes au niveau des infections intestinales. Le tableau I récapitule les entérotoxines bactériennes associées à une diarrhée et dont le récepteur membranaire est connu.

\subsection{Nature et structure d'un récepteur}

Les récepteurs pour les entérotoxines bactériennes présentent une diversité au niveau de leurs fonctions et également au niveau de leurs structures et de leurs spécificités. Dans les mécanismes moléculaires de pathogénèse, la grande majorité des associations connues apparaît basée sur la reconnaissance spécifique d'un ligand protéique par un glycoconjugué à la surface de la cellule hôte (récepteur). Le plus souvent, la partie glycosylée est impliquée dans la spécificité de l'attachement [9, 30, 34, 75]. Dans le cas des toxines bactériennes entériques, les sites d'attachement glycosylés, dont les structures sont les mieux décrites, sont le monosialoganglioside GM1, pour les toxines CT et toxine thermolabile d'E. coli (LT), et le globotriosylcéramide Gb3 pour les vérotoxines.

Des interactions protéine-protéine, comme la reconnaissance de récepteurs par une adhésine de nature protéique, sont également connues entre pathogène et la cellule hôte [5]. La séquence en acides aminés détermine le site d'attachement [73]. En général, chez les toxines bactériennes, les 


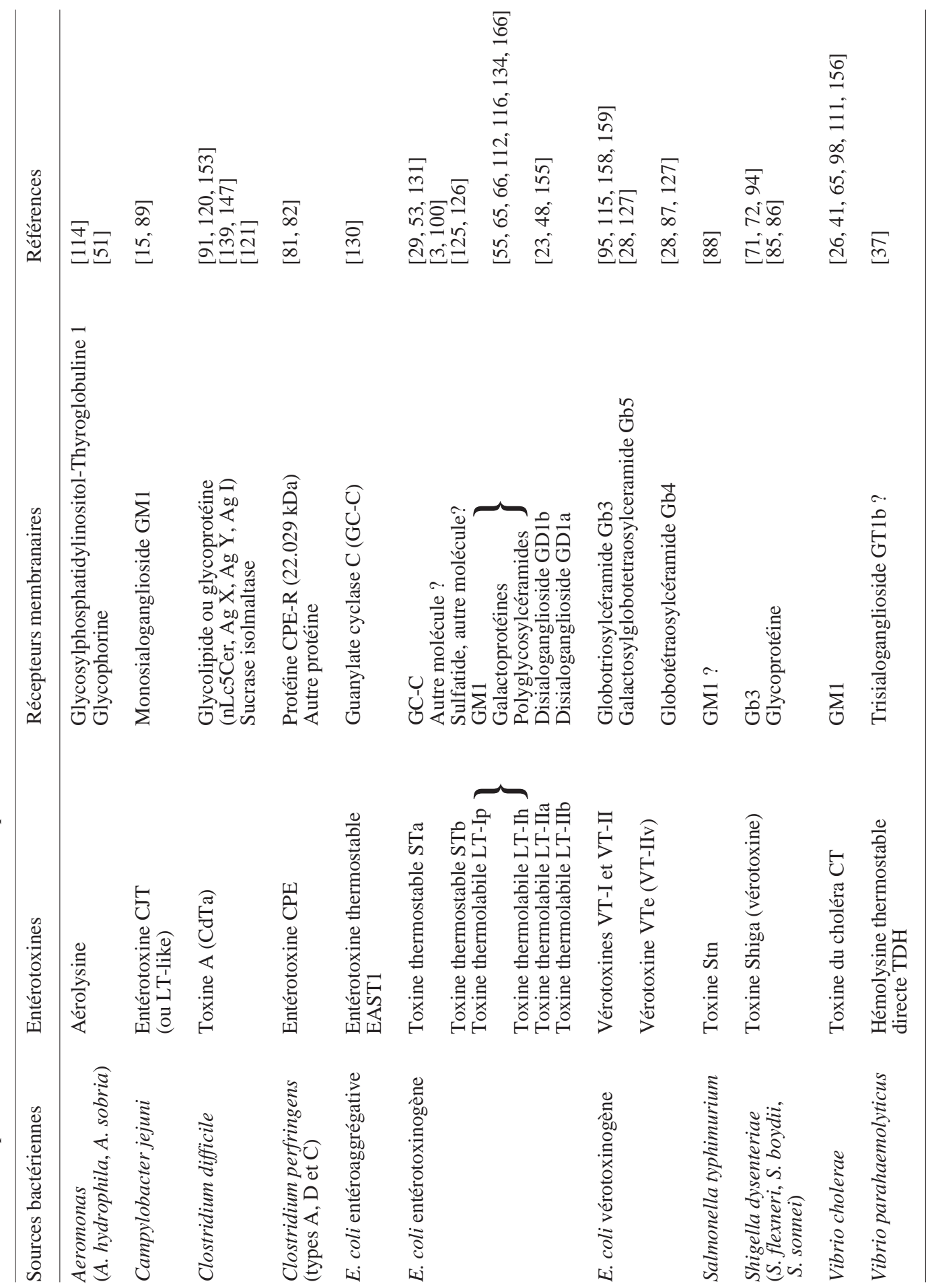


toxines possédant plusieurs domaines d'attachement, comme CT, LT ou VT, reconnaissent la partie glucidique portée par des lipides ou des protéines, alors que les toxines présentant un seul domaine d'attachement, comme la toxine diphtérique ou la toxine STa, semblent reconnaître un site protéique [64a, 157].

Par ailleurs, des entérotoxines reconnaissent des sites sur de simples lipides membranaires (le cholestérol, les phospholipides, tels que la phosphatidylcholine, et les sphingolipides, tels que la sphingomyéline). Dans la plupart des cas, ce sont les toxines endommageant la membrane plasmique. Ces toxines peuvent utiliser certains lipides, non comme récepteur membranaire, mais plutôt comme accepteur de faible affinité $[43,104]$. Les lipides sont des composants fondamentaux et très abondants de la membrane plasmique et ils sont répandus sur différents types cellulaires. Ainsi, leur abondance permet à certaines toxines de les reconnaître et de s'y attacher avec une affinité restreinte.

\subsection{Reconnaissance et attachement à un glycoconjugué}

\subsubsection{Caractéristiques des glycoconjugués présents à la surface des cellules}

Plusieurs caractéristiques peuvent expliquer pourquoi les glycoconjugués sont le plus souvent impliqués comme sites d'attachement spécifiques parmi les constituants de surface cellulaire. Leur caractéristique majeure est leur abondance à la surface de la cellule animale, notamment des cellules épithéliales des muqueuses, site de colonisation normal des bactéries et porte d'entrée principale des infections. Les chaînes glucidiques détectées à la surface des membranes cellulaires sont composées de 1 à 20 sucres dont les plus connus sont le glucose, le galactose, le mannose, le fucose ou les sucres aminés, comme la N-acétylglucosamine, la $\mathrm{N}$-acétylgalactosamine et l'acide neuraminique $[69,70]$. Par conséquent, ces structures saccharidiques exposées à la surface des cellules sont des sites privilégiés pour la reconnaissance des toxines bactériennes, notamment dans l'intestin.

Les glycoconjugués membranaires sont présents sous différentes formes : glycoprotéines, protéoglycans et glycolipides. Ces glycoconjugués ont une portion hydrophobe de leur molécule solidement ancrée dans la membrane cellulaire et une portion saccharidique exposée à la surface externe de cette membrane. Les glycoconjugués les moins fortement associés aux membranes sont les glycoprotéines, telles que les mucines et les protéoglycans, dans la mesure où ces molécules peuvent être sécrétées [119]. Les glycoconjugués protéiques ont plusieurs chaînes, souvent différentes, liées au même peptide. Ces chaînes sont liées aux sérines (S) ou aux thréonines (T), formant une liaison O-glycosidique, ou liées aux asparagines (N) formant une liaison N-glycosidique. La partie peptidique peut traverser la membrane. En revanche, les glycolipides ont la particularité de porter une seule chaîne saccharidique par molécule. La partie lipidique semble exclusivement localisée dans le feuillet externe de la bicouche lipidique. Dans la plupart des cas, les glycolipides sont strictement liés à la membrane et sont absents des sécrétions [79]. Toutefois, l'intestin dispose d'un très rapide renouvellement de cellules épithéliales, qui sont libérées de l'épithélium et dégradées dans la lumière intestinale. C'est pourquoi les glycolipides peuvent être présents dans le mucus intestinal.

La majorité des glycoconjugués de la surface cellulaire jouent un rôle dans la protection et l'intégrité de la structure de la cellule. C'est le cas essentiellement des chaînes riches en mannose liées en $\mathrm{N}$ - aux protéines. Ces chaînes sont abondantes à la surface des cellules et ne semblent montrer que peu de variation entre les espèces, individus, tissus et cellules. En revanche, les chaînes liées en $\mathrm{O}$ - aux protéines, comme dans les 
mucines qui ne contiennent pas de mannose, et les chaînes liées aux lipides démontrent une forte variation. Les chaînes liées en Odes glycoprotéines semblent porter les mêmes séquences que les chaînes des glycolipides, à l'exception du premier monosaccharide, qui est généralement le GalNAc alpha au lieu du Glc bêta pour les glycolipides. La complexité de ces chaînes augmente en fonction de l'évolution des espèces. Les chaînes diffèrent par la nature, le nombre et l'agencement des sucres. Ces derniers jouent un rôle fondamental quant à l'affinité des glycoconjugués pour certaines toxines. Il existe un grand nombre de spécificités d'attachement avec la partie glycosylée des glycoconjugués. Cette grande variabilité structurale des chaînes saccharidiques, comparée à la séquence en acides aminés des protéines, favorise la possibilité de récepteurs multiples grâce à très peu de changement sur le ligand.

La topologie moléculaire et le réarrangement des molécules à la surface cellulaire sont également des éléments importants dans l'attachement et la pénétration d'une toxine. La partie glycosylée d'une glycoprotéine est en général plus longue et apparaît plus exposée et plus accessible que la partie glycosylée d'un glycolipide. De plus, les constituants lipidiques et protéiques d'une bicouche ne sont pas immobiles, mais en perpétuel mouvement. Cette situation dynamique au niveau de la surface cellulaire autorise des diffusions latérales et des échanges de position par les molécules ancrées dans la bicouche lipidique. Pour accéder à un site très proche de la membrane, il semble que le ligand requiert l'induction d'une diffusion latérale des composants masquant la surface. Cette théorie a d'ailleurs été émise pour l'adhésion cellulaire [6]. Le modèle cinétique d'adhésion cellulaire décrit indique que les forces de répulsion impliquées, lors du rapprochement d'une particule, semblent induire une diffusion latérale et une réorganisation des composants de surface permettant alors un attachement de faible énergie.

\subsubsection{Interaction de type «clé-serrure»}

Un attachement peut avoir lieu soit par une association non-spécifique, souvent de nature non polaire, soit par une interaction spécifique de type «clé-serrure », comparable à la combinaison d'un antigène avec son anticorps ou d'une enzyme avec son substrat $[13,77,117,150]$. Le plus souvent, l'association est spécifique ce qui permet de former des complexes stables et de conférer une activité au complexe formé.

La reconnaissance moléculaire de deux protéines entre elles ou d'une protéine et d'un site saccharidique dépend de la complémentarité stérique et électrostatique des surfaces se combinant. L'ajustement serré des deux surfaces rend compte du fait que la fixation spécifique est une interaction non covalente extrêmement solide. Plus la spécificité est grande, plus le profil moléculaire du ligand épouse la forme du site d'attachement. La conformation cristallographique des complexes ligand-récepteur montre généralement la séquence d'attachement prenant place entre deux domaines majeurs du ligand protéique, qui enserrent un site actif placé dans une poche. Les deux lobes sont souvent assez hydrophobes, alors que la poche de fixation est hydrophile. Le site spécifique à une séquence saccharidique ressemble à une cavité pour l'attachement de courtes séquences terminales et à un sillon profond, ou crevasse, pour des séquences plus longues ou internes [79].

Certaines forces électrostatiques entrent en jeu dans la reconnaissance entre les groupements du site d'attachement saccharidique et les acides aminés du site actif du ligand. Généralement, les chaînes latérales de ces acides aminés sont engagées dans des liaisons hydrogènes. Le ligand protéique interagit avec des groupements polaires d'oxygène ou d'azote très proches, qui sont issus des unités saccharidiques. Parfois, les acides aminés du site actif portent des sites anioniques ou cationiques qui entrent en jeu dans la reconnaissance via des liaisons ioniques. Ces interactions fortement polaires déter- 
minent entièrement la spécificité de l'attachement.

En plus de ces forces polaires, la séquence saccharidique expose une surface à caractère non polaire. Cette dernière est formée d'un anneau d'atomes d'hydrogène qui s'étend autour des groupements polaires. Cette surface va former un contact hydrophobe avec les chaînes latérales d'acides aminés hydrophobes appartenant à la protéine complémentaire. Ce contact est la contribution majeure pour la stabilité du complexe. Les interactions hydrophobes sont connues, en effet, pour jouer un rôle crucial dans le maintien des structures moléculaires.

\subsubsection{Reconnaissance de séquences internes - Isorécepteurs}

Les ligands des micro-organismes à activité lectine partagent la propriété de reconnaître des séquences terminales, mais aussi internes dans la chaîne saccharidique $[4,10$, 80], à la différence de la plupart des anticorps qui reconnaissent des parties terminales seulement [150]. Cette propriété est à l'origine du terme « isorécepteurs ».

Un groupe de glycoconjugués peut présenter un même site d'attachement placé à différents endroits dans la chaîne. Les isorécepteurs possèdent une séquence minimale d'attachement en commun, mais des groupements voisins distincts. Les sites saccharidiques d'attachement identiques, retrouvés à différentes positions, vont par conséquent présenter des conformations préférentielles pour l'accessibilité du site par le ligand. La spécificité d'attachement est une notion large par rapport au site minimal d'attachement (ou épitope d'attachement). La conformation environnante de l'épitope d'attachement confère une affinité optimale parmi une famille d'isorécepteurs. La toxine Shiga, par exemple, reconnaît le disaccharide Gal(alpha 1-4)Gal [94]. Parmi une série d'isorécepteurs portant ce disaccharide en position terminale ou interne, plusieurs sont reconnus par la toxine. Cepen- dant, le globotriosylcéramide Gb3 présente la plus forte affinité et joue également un rôle important dans le tropisme de la toxine $[11,12]$.

La reconnaissance du site en position interne de la chaîne est une activité lectine unique pour le ligand. Des différences existent dans la composition des glycoconjugués en fonction des espèces animales et des tissus et les variations observées résident majoritairement dans la partie terminale de la chaîne saccharidique formant la molécule. L'attachement à un isorécepteur représente un avantage pour la toxine nécessitant un attachement à la muqueuse, car elle évite ainsi les différences présentes en position terminale.

\subsubsection{Attachement de faible affinité}

L'affinité du complexe est généralement mesurée par la constante d'association $\mathrm{K}_{\mathrm{A}}$ ou la donnée inverse, la constante de dissociation $\mathrm{K}_{\mathrm{D}}$. La constante $\mathrm{K}_{\mathrm{A}}$ varie entre $10^{7}$ et $10^{11} \mathrm{M}^{-1}$ pour les complexes anticorpsantigène qui sont de forte affinité [13]. Même si les systèmes de forte affinité existent, ceux de faible affinité sont souvent sélectionnés par les toxines bactériennes et de nombreux autres ligands de pathogènes [80].

La constante d'association du récepteur de STa est forte (environ $10^{9} \mathrm{M}^{-1}$ ) [58]. Plus la valeur de $\mathrm{K}_{\mathrm{A}}$ est forte, plus la toxine se fixe fermement à son récepteur. Cet attachement de forte affinité est inhibé par la molécule récepteur sous forme soluble, même à de faibles concentrations. En revanche, le site galabiose (Gal(alpha 1-4)Gal), reconnu par la toxine Shiga (Stx), n'est pas un compétiteur efficace. L'attachement de la toxine Shiga avec les cellules cibles n'est pas inhibé par des concentrations élevées du disaccharide Gal(alpha 1-4)Gal libre. La constante $K_{A}$ d'un site d'attachement d'une sous-unité $B$ de la toxine est de l'ordre de $10^{3} \mathrm{M}^{-1}$. Un attachement de faible affinité n'est pas inhibé par un oligosaccharide soluble univalent, 
même à des concentrations élevées. Par conséquent, les méthodes classiques de compétition, basées sur l'inhibition avec des oligosaccharides solubles, ne peuvent pas être utilisées pour démontrer la spécificité de l'attachement. En fait, la toxine Shiga nécessite une multivalence de la séquence disaccharide pour un attachement efficace avec les cellules cibles [94]. Lorsque le site Gal (alpha 1-4)Gal est présenté de façon multivalente en conjugaison avec de la sérum albumine bovine (SAB), l'inhibition est efficace. L'inhibition est optimale lorsque 25 résidus de Gal(alpha 1-4)Gal sont liés avec la SAB. Aucune inhibition n'est obtenue avec le composé (Gal (alpha 1-4)Glc) ${ }_{25}{ }^{-}$ $\mathrm{BSA}$, où le lactose, au lieu du galabiose, est lié avec la $\mathrm{SAB}$.

Le site d'attachement de faible affinité doit être présenté sous sa forme multivalente à la surface des cellules et ce phénomène est largement influencé par l'état de la membrane, en particulier par sa fluidité [140]. L'attachement de la toxine CT requiert aussi un attachement multivalent [41]. Il est supposé qu'une molécule de toxine CT s'attache, premièrement, à une seule molécule de GM1, et se déplace alors latéralement à la surface de la membrane plasmique de façon à rencontrer une autre molécule de GM1. Similairement à la toxine Shiga, l'affinité d'attachement pour une seule sous-unité B de CT avec l'oligosaccharide porté par GM1 est plutôt faible. Cependant, comme l'attachement de CT avec la membrane est pentavalent, la constante d'association de la toxine avec la cellule est forte (de l'ordre de $10^{10} \mathrm{M}^{-1}$ ).

Karlsson et al. [80] estiment que l'attachement de faible affinité relève d'une complémentarité insuffisante entre la protéine et le site saccharidique. Pour qu'un inhibiteur (de synthèse, par exemple) de cet attachement soit efficace en compétition, il faut que le site saccharide soit multivalent ou, s'il est univalent, que l'affinité des sites individuels soit augmentée par rapport à l'affinité naturelle. Ce type d'attachement de faible affinité apparaît constituer un avantage à la surface des cellules. Il est fort probable qu'il ait été sélectionné de façon à contrer les inhibitions par des oligosaccharides solubles et univalents présents à la surface des cellules cibles en raison de diverses dégradations enzymatiques.

\section{VARIANTS DE LIGANDS}

Il est fréquent de rencontrer des variants de ligands. Ces ligands diffèrent légèrement dans leurs spécificités d'attachement. Chaque famille de spécificité d'attachement est corrélée avec des ligands nécessitant la même séquence minimale. Cependant, les toxines se distinguent par leurs préférences pour certains isorécepteurs. Par conséquent, les sites d'attachement complémentaires des ligands protéiques doivent être apparentés au niveau structural [80]. Des mutations de ces ligands, affectant un ou quelques acides aminés, sont suffisantes pour induire des modifications structurales fines du site et conduire à un changement de spécificité d'attachement entre deux isorécepteurs. En revanche, ces mutations doivent être beaucoup plus importantes pour conduire à un changement entre deux familles d'isorécepteurs. L'attachement à une séquence terminale présentant une séquence voisine d'un seul côté nécessite des mutations importantes si le changement de spécificité du ligand s'oriente vers la reconnaissance d'une séquence interne.

De telles modifications des ligands peuvent expliquer les changements dans la sélectivité de divers tissus de l'hôte pour l'infection. Par exemple, le récepteur membranaire de la toxine Stx2e, de la maladie de l'œdème du porc, est le globotétraosylcéramide $\mathrm{Gb} 4$ ou globoside, alors que c'est le Gb3 pour la toxine Stx2 [28]. Le site minimal d'attachement est la séquence Gal(alpha 1-4)Gal, à la fois pour la toxine Stx2 et pour le variant de Stx2e. Il a été montré qu'un changement dans l'attachement par les vérotoxines entre le Gb4 (pour Stx2e) et le Gb3 (pour Stx2 et Stx1) peut expliquer la diffé- 
rence du tropisme cellulaire de l'infection respectivement chez le porc et l'humain [127].

\section{SITES D'ATTACHEMENT MULTIFACTORIELS}

L'attachement multifactoriel définit l'existence de plusieurs spécificités d'attachement pour un même ligand. Une spécificité d'attachement multiple peut résulter en un ou plusieurs récepteurs alternatifs pour une toxine. Par exemple, comparativement au récepteur ubiquitaire GM1 de CT et LT, le récepteur GC-C de STa est présent uniquement dans l'intestin. La stimulation de GC-C par STa est plus grande dans l'intestin grêle que dans le côlon $[58,92]$ et, en général, moins de récepteurs à STa sont trouvés dans le côlon $[21,90]$. En revanche, la réponse à STa en flux d'électrolytes, telle que mesurée en chambre d'Ussing, est plus forte dans le côlon [92]. Il est possible que la toxine STa soit inactivée à différents niveaux dans différentes régions de l'intestin, comme il a été montré dans le jéjunum et l'iléon [22]. Une autre hypothèse est basée sur la présence de récepteurs pour STa «non GC-C » dans le côlon [33]. Dans ce cas, les récepteurs non $\mathrm{GC}-\mathrm{C}$ pourraient être corrélés à une voie de signalisation alternative, permettant cette plus forte réponse en flux d'électrolytes dans le côlon. La présence d'un nouveau récepteur pour STa est fortement suggérée [2, 3, 100].

Dans le cas de plusieurs toxines bactériennes, des résultats récents s'orientent vers un mécanisme d'attachement en deux étapes ou plus. Le site d'attachement pour la première étape serait impliqué dans le ciblage et le tropisme de l'infection. Le site d'attachement pour la deuxième étape servirait à établir un attachement membranaire. $\mathrm{Ce}$ mécanisme a été proposé pour la toxine LT, considérant que l'attachement de l'anneau de sous-unités B au GM1 devait être précédé de l'attachement avec un site plus distant de la membrane cellulaire. Il a été observé que la toxine LT démontre un attachement 10 fois plus fort que la toxine CT dans le petit intestin de lapin. Un site récepteur membranaire additionnel à GM1 pour LT a désormais été identifié $[4,55,65,116,134,166]$. Il est surprenant que deux espèces bactériennes qui colonisent le même tissu, l'intestin grêle, et utilisent les mêmes récepteur et cible d'action pour leurs toxines, diffèrent dans l'adhérence initiale de la bactérie au tissu. Il est possible que les deux espèces bactériennes adhèrent à des récepteurs différents et qu'ensuite, les toxines élaborées par la bactérie soient dirigées vers leurs récepteurs. L'attachement de la toxine avec les groupements N-acétyl lactosamine (Gal(bêta 1-4)GlcNAc) des glycoprotéines ou des polyglycosylcéramides plus allongés serait suivi de l'attachement clé au GM1, très proche de la bicouche lipidique. De cette manière, les glycolipides courts, comme GM1, qui sont souvent peu accessibles directement du fait de la présence de chaînes saccharidiques plus étendues, deviendraient alors accessibles suite à la première étape d'attachement. De façon similaire, Lindberg et al. [94] ont constaté que certaines lignées cellulaires sont résistantes à l'action de la toxine Shiga (internalisation et arrêt de la synthèse protéique), alors que les sites récepteurs sont présents en densité élevée. Ces résultats suggèrent qu'il existe au moins deux classes de récepteurs distincts sur le plan fonctionnel et qui ne sont pas toujours produites. Les auteurs proposent que l'attachement au site galabiose, à proximité de la bicouche lipidique, corresponde à un récepteur fonctionnel pour la pénétration de la toxine, alors que d'autres sites plus éloignés vont permettre l'attachement avec la surface cellulaire, mais pas la pénétration.

La sensibilité de l'hôte vis-à-vis d'une infection est significativement dépendante de ses caractéristiques spécifiques, comme l'espèce, l'âge ou la lignée génétique. La distribution des sites d'attachement peut expliquer très souvent le tropisme d'un micro-organisme et notamment d'une toxine [108, 109]. 


\section{DIVERSITÉ FONCTIONNELLE DES ENTÉROTOXINES}

\subsection{Activation de l'adénylate cyclase}

Parmi les mécanismes d'action établis chez les entérotoxines bactériennes, le mieux compris à un niveau moléculaire est celui de la toxine cholérique (CT). De nombreuses études ont montré que $\mathrm{CT}$ reconnaissait un récepteur spécifique unique, le glycolipide GM1 (Fig. 2), à la surface de nombreuses cellules et induisait une élévation du taux d'AMPc proportionnel au nombre de sites reconnus [26, 40, 41, 56, 67, 156].

La toxine CT exerce son activité toxique en se fixant à la surface cellulaire, par l'intermédiaire de ses cinq sous-unités B. Les sousunités B forment une structure pentamérique très stable, tel un anneau étroit, avec un trou central, où est reliée la sous-unité $\mathrm{A}$ [135, 137, 138]. La sous-unité A comprend deux composants (A1 et A2) générés par protéolyse et reliés par un pont disulfure. Le fragment A1 possède l'activité ADPribosyltransférase et le fragment A2 assure la liaison de la sous-unité $\mathrm{A} 1$ au pentamère de sous-unités B. Chaque sous-unité B porte un site d'attachement spécifique de la portion glucidique du ganglioside GM1. Les cinq sous-unités de la toxine CT s'attachent à cinq molécules de GM1 [107]. Les sites d'attachement des sous-unités B sont localisés au niveau de la surface externe du cylindre formé par le pentamère. Ainsi, un attachement étroit a lieu entre la base de l'anneau de sous-unités B et la bicouche, par l'intermédiaire de saccharides liés à des lipides.

L'attachement à la cellule induit soit la translocation rapide de la sous-unité A1 directement à travers la membrane, soit l'endocytose de la toxine CT avec le fragment A1 restant associé à la membrane endosomale. Le mécanisme d'insertion membranaire n'est pas très clair [136, 148]. Il est proposé que le clivage du pont disulfure, libérant le fragment A1, rende ce fragment hydrophobe. De plus, les sous-unités B joueraient un rôle important dans l'orientation topologique de ce fragment par rapport à la surface membranaire. A l'intérieur de la cellule, la sous-unité A1 catalyse l'ADPribosylation d'une arginine (R201) de la sous-unité alpha de la protéine stimulatrice Gs de l'adénylate-cyclase intestinale [93]. Cette ADP-ribosylation bloque l'activité GTPase de la sous-unité alpha. La sousunité alpha liée au GTP active alors en permanence la sous-unité catalytique de l'adénylate-cyclase. Une production constitutive

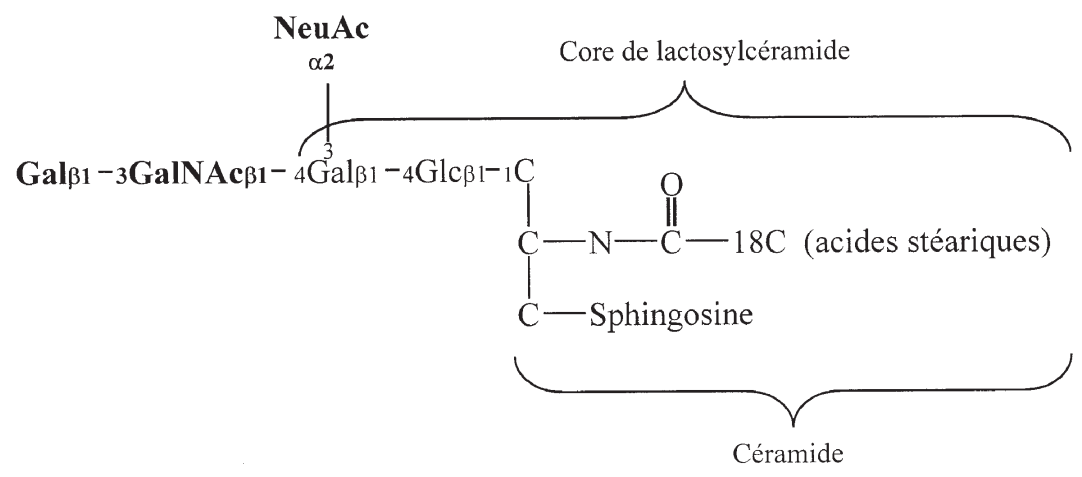

Figure 2. Structure du monosialoganglioside GM1, le récepteur commun aux toxines CT et LT. L'acide $\mathrm{N}$-acétyl neuraminique (NeuAc) fait partie de la structure des gangliosides. 
d'AMPc intracellulaire est ainsi déclenchée. Cette augmentation d'AMPc active les protéines kinases dépendantes de l'AMPc (PKA), ce qui entraîne la phosphorylation de protéines membranaires, notamment les canaux de transport des ions, tels que les canaux CFTR (Cystic Fibrosis Transmembrane Regulator), pour la sécrétion des ions chlore dans la lumière intestinale [18] (pour illustration voir [64b]).

La toxine LT d'E. coli reconnaît également le récepteur membranaire GM1, par l'intermédiaire de ses sous-unités B, et conduit aux mêmes effets dans les cellules et dans l'intestin que la toxine CT [56, 65, 133 , 136]. Alors que la toxine CT s'attache au GM1 avec une grande sélectivité, la toxine LT fixe d'autres récepteurs membranaires, non reconnus par $\mathrm{CT}$, et qui sont fonctionnels pour LT [55, 67, 116, 134, 166]. En raison de la présence souvent en grand nombre de récepteurs fonctionnels, uniquement reconnus par LT, l'attachement et la réponse de LT n'est pas inhibée par les sousunités $\mathrm{B}$ de la toxine $\mathrm{CT}$ ajoutée en excès in vitro [67]. Le ganglioside GM1 semble être aussi le récepteur de l'entérotoxine CJT de Campylobacter jejuni, qui est une toxine apparentée à LT [15, 89]. Par contre, l'aérolysine d'Aeromonas (A. hydrophila et A. sobria, notamment) induit des effets semblables à ceux de CT et de LT, notamment l'augmentation d'AMPc intracellulaire, mais ne reconnaît pas GM1 [19]. L'aérolysine est tout de même assez éloignée fonctionnellement de CT et LT. Elle n'est pas seulement cytotonique, mais aussi cytotoxique, car elle induit la formation de pores membranaires [19].

\subsection{Activation de la guanylate cyclase}

Une classe de toxines bactériennes entériques stimule directement une guanylatecyclase, augmentant le taux intracellulaire de GMPc à l'origine de la perte des électrolytes. L'exemple le plus connu est celui de la toxine thermostable STa d'E. coli [33].
La toxine STa fixe et stimule la guanylate cyclase de type C (GC-C), qui est une protéine transmembranaire $\mathrm{N}$-glycosylée, de 140 à 160 kDa, localisée au pôle apical des cellules épithéliales intestinales [44, 53, 106, $131,154]$.

L'attachement de STa à ce récepteur de surface cellulaire (GC-C) induit un changement de conformation propageant la transduction du signal du côté intracellulaire, c'est-à-dire au niveau du domaine catalytique de l'enzyme. La protéine kinase C (PKC) phosphoryle et active ce domaine intracellulaire. Le site de phosphorylation serait la sérine en position 1029 du GC-C pour la PKC [25]. Ainsi, suite à l'attachement de STa, une production de GMPc est déclenchée, qui conduit à l'augmentation de la sécrétion intestinale de chlore et à l'inhibition de l'absorption de sodium [39, $42,57,68,118]$ (pour illustration voir [33]).

Le ligand naturel qui stimule l'enzyme GC-C chez les mammifères est la guanyline, un peptide de 15 acides aminés présentant $50 \%$ d'homologie avec la toxine STa [27, 54]. Plusieurs autres toxines thermostables apparaissent appartenir à la même classe que STa. La toxine EAST1 des $E$. coli entéroaggrégatives est très apparentée à la guanyline. Le domaine d'attachement de la guanyline et de l'entérotoxine STa avec le récepteur protéique GC-C serait identique à celui de EAST1 [130, 164]. La toxine thermostable de Yersinia enterocolitica, souvent impliquée dans les gastroentérites de l'enfant, rappelle également STa par sa structure similaire, son récepteur et son mode d'action communs [124, 145].

\subsection{Voie du calcium}

Les ions $\mathrm{Ca}^{2+}$ sont soit sous forme libre, à une concentration maintenue à environ $100 \mathrm{mM}$ dans la plupart des cellules, soit en réserve, à des concentrations plus élevées dans différents compartiments, tels que les fluides extracellulaires ou intersticiels, les mitochondries et le réticulum endoplas- 
mique. Plusieurs voies signalisatrices du calcium sont connues. Néanmoins, les mécanismes sont très peu connus pour les entérotoxines qui stimulent une sécrétion par des mécanismes dépendants de voies du calcium.

Quelques données suggèrent également un mécanisme dépendant du calcium pour l'hémolysine thermostable directe (TDH) de Vibrio parahaemolyticus [122, 146a]. Tang et al. [146a] suggèrent que l'hémolyse causée par TDH consiste en un processus comportant au moins deux étapes, soit un attachement à la surface des érythrocytes précédant un attachement nécessaire à la formation de pores membranaires. Cette toxine apparaît s'attacher au trisialoganglioside GT1b comme récepteur de surface cellulaire [122, 165].

D'après les informations obtenues ces cinq dernières années, la toxine $\mathrm{STb}$ d' $E$. coli appartient à cette catégorie, dont l'action initiale conduit à l'augmentation du taux de $\mathrm{Ca}^{2+}$ dans le cytosol [32]. Seules les étapes se déroulant dans les cellules épithéliales seraient dépendantes du calcium, alors que le mécanisme de libération de la 5-hydroxytryptamine (5-HT) par les cellules entérochromaffines de la base des villosités serait indépendant du calcium [61]. Le calcium intracellulaire active le métabolisme de l'acide arachidonique pour la synthèse de la prostaglandine E2 (PGE2) [46], mais la voie principale serait celle de la calmoduline [47]. Les différentes étapes seraient les suivantes : 1) la toxine $S T b$ se fixe à un récepteur membranaire, le sulfatide $[125,126]$ qui activerait une protéine $G$, stimulant l'ouverture d'un canal et l'entrée du $\mathrm{Ca}^{2+}$ extracellulaire dans la cellule [31], 2) le $\mathrm{Ca}^{2+}$ intracellulaire active la calmoduline, une protéine complexant le $\mathrm{Ca}^{2+}$, qui à son tour active la kinase II dépendante de la calmoduline [47], 3) la kinase II activée va probablement catalyser la phosphorylation de certaines protéines, telles que des protéines membranaires de transport des ions (pour illustration voir [33]).

\subsection{Réarragement du cytosquelette}

Une autre voie utilisée par les toxines bactériennes entériques pour communiquer avec les cellules intestinales est le réarrangement du cytosquelette. Le cytosquelette des entérocytes aide à maintenir la polarité et la structure des cellules épithéliales. L'actine est présente dans les cellules sous deux formes majeures : l'actine $\mathrm{G}$ monomérique (globulaire) et l'actine F polymérique (filamenteuse). Cette dernière est le constituant principal des microfilaments du cytosquelette et des fibres de stress des cellules. L'actine $\mathrm{F}$ est donc à la base de la forme de la cellule et surtout à la base de fonctions cellulaires essentielles, telles que la motilité, l'adhésion, la phagocytose et la division.

Les entérotoxines les plus représentatives de cette catégorie sont des toxines clostridiales, comme la toxine $\mathrm{C} 2$ de Clostridium botulinum $[1,45]$ ou la toxine A de Clostridium difficile (ou CDTa). Le récepteur de CDTa a été le plus étudié parmi ceux des entérotoxines ayant une activité dirigée contre l'actine [20, 91, 120, 121, 129, 139, 147, 152]. CDTa est cytotonique et peut exercer aussi des effets cytotoxiques [153]. L'activité enzymatique intrinsèque de la toxine A est l'activité glucosyltransférase. Elle modifie une thréonine (T37) des petites protéines $\mathrm{G}$ monomériques de sous-type Rho. L'addition d'une seule molécule de glucose bloque l'association de la protéine Rho avec son effecteur, dissociant les microfilaments d'actines F du cytosquelette endothélial, important dans la fonction de barrière de l'endothélium [63, 76] (pour illustration voir [146b]). Toutefois, l'identification du récepteur n'est toujours pas clairement établie. Il semble que plusieurs récepteurs, à la fois de nature glycoprotéique et glycolipidique, soient reconnus au niveau des cellules épithéliales intestinales [139]. 


\subsection{Arrêt de la synthèse protéique}

La vérotoxine (ou toxine Shiga) de Shigella dysenteriae type 1 (Stx) et les vérotoxines VT (ou Stx1 et Stx2), apparentées chez E. coli, sont des toxines A-B [74, 99, $115,141]$, pour lesquelles le mécanisme d'action a été partiellement élucidé. Les vérotoxines provoquent un détachement et une destruction irréversible qui fut observée, à l'origine, sur des cellules Véro en culture et induisent une réponse sécrétoire et entéronécrosante dans l'intestin. L'activité sécrétoire est encore mal comprise, mais l'effet cytotoxique est aujourd'hui bien expliqué [59, 144].

L'attachement du pentamère de sous-unités B induit l'entrée de la sous-unité A dans la cellule [128]. La toxine est internalisée par voie endocytosique et les vésicules formées, contenant la toxine, fusionnent avec des lysosomes. La sous-unité A1, provenant du clivage du composant $\mathrm{A}$ (par réduction d'un pont disulfure), passe dans le cytosol, où elle s'associe à la sous-unité $60 \mathrm{~S}$ du ribosome [123]. L'activité N-glycosidase de la sous-unité A1 clive l'adénine en position 4324 de l'extrémité 3' de l'ARNr 28S du complexe ribosomal, inhibant l'action du facteur d'élongation peptidique et donc la synthèse protéique [36, 148]. L'inhibition de la synthèse protéique aboutit à la mort de la cellule. Ce mécanisme rend compte de l'activité entéronécrosante de la vérotoxine. L'effet sécrétoire serait corrélé à la destruction des cellules épithéliales impliquées dans l'absorption intestinale du sodium.

Le pentamère de sous-unités $B$ de la vérotoxine se fixe aux membranes cellulaires sur un récepteur spécifique. Le globotriosylcéramide Gb3 (le glycolipide du groupe sanguin $\mathrm{P}$ ) est le récepteur à la fois pour la toxine Shiga et pour les toxines Stx1 et Stx2 [71, 94, 159]. Le récepteur de la toxine Shiga a été mis en évidence principalement sur les cellules HeLa et les cellules Véro. En fait, peu de lignées cellulaires reconnaissent cette toxine et il est intéressant de remarquer que, mis à part les cellules Véro, seules les cellules humaines y sont sensibles [35]. Il a été montré que la toxine Shiga ne s'attache in vivo qu' aux cellules villositaires qui contiennent Gb3 et non aux cellules cryptiques qui sont démunies de ce glycolipide [78]. Cet attachement sélectif permet à la toxine Shiga d'affecter essentiellement l'absorption du sodium, propre aux cellules du sommet des villosités, et d'altérer légèrement et indirectement la sécrétion de chlore par les cellules cryptiques à la base des villosités.

\subsection{Formation de pores membranaires}

Plusieurs entérotoxines bactériennes exercent une action commune sur la membrane plasmique des cellules, à savoir la formation de pores. L'insertion membranaire d'une toxine avec création d'un pore dans la bicouche lipidique est un mécanisme encore hypothétique dans le cas des toxines bactériennes entériques. Il est d'ailleurs possible que la formation de pores ne soit pas suffisante pour causer une réponse sécrétoire du tissu intestinal. Par exemple, la toxine TDH et la toxine de Clostridium perfringens (CPE) citées plus haut peuvent causer la formation de canaux perméables aux ions et le mécanisme utilisé apparaît principalement être dépendant des voies du calcium. Ainsi, l'entérotoxine CPE est essentiellement cytotoxique, probablement en provoquant un arrêt de la synthèse protéique, mais elle induit aussi une réponse sécrétoire en anses ligaturées. Ses effets physiologiques sont en grande partie dus à un changement de la perméabilité des cellules, et notamment à un influx de $\mathrm{Ca}^{2+}[101,103 a]$. CPE semble agir sur les cellules épithéliales par un mécanisme en plusieurs étapes : attachement avec la surface cellulaire, insertion membranaire, puis formation d'un pore perméable aux ions [60, 102, 142]. Le pore est constitué d'un hétérocomplexe entre la molécule de toxine et deux protéines membranaires de 70 et $50 \mathrm{kDa}$ [82, 162, 163]. L'attachement 
et l'insertion membranaire sont des étapes indépendantes des cations divalents, alors que les étapes consécutives sont dépendantes du calcium [133]. La fixation de CPE sur les entérocytes impliquerait deux classes distinctes de récepteurs protéiques, dont un a été récemment cloné [81, 82].

De manière générale, il semble que la concentration de toxine soit importante dans l'attachement des toxines formant des pores. La toxine alpha de $S$. aureus est la mieux connue parmi ces toxines. Il a été montré que l'attachement de la forme monomérique de la toxine alpha peut avoir lieu soit avec un récepteur protéique spécifique de forte affinité [62], soit avec des lipides [43]. Le processus d'oligomérisation, d'insertion et de formation d'un pore transmembranaire semble dépendre de la présence de récepteurs spécifiques lorsque la concentration de toxine est très faible à la surface cellulaire. Les récepteurs ont probablement pour rôle de concentrer la toxine par diffusion latérale à la surface de la bicouche, favorisant alors l'oligomérisation et l'insertion (pour illustration voir [103b]). Le mode d'action pour la formation de pores par l'aérolysine d'Aeromonas est apparenté à celui de la toxine alpha. Les pores de l'aérolysine sont légèrement sélectifs en anions, à la différence des pores formés par CPE et TDH [16]. L'aérolysine s'attache aux cellules par un récepteur et forme alors un canal heptamérique dans la membrane [14, 110, 161]. L'attachement précède l'étape d'oligomérisation et cette dernière est requise pour la formation du pore dans la bicouche lipidique [51]. Les sites requis pour l'attachement sont distincts de ceux nécessaires à l'oligomérisation et à la formation de pores. Le récepteur fonctionnel de l'aérolysine serait la glycophorine dans certains cas, ou la thyroglobuline-1 ancrée à un glycosylphosphatidylinositol (GPI) [14, 24, 51, 114]. Il est important de noter que les protéines ancrées au GPI ont le potentiel d'une très grande mobilité latérale, ce qui est un avantage pour une toxine qui doit devenir com- pétente dans l'oligomérisation après l'attachement pour s'insérer dans la membrane.

Des structures secondaires caractéristiques sont partagées par les toxines formant des pores. La toxine alpha de $S$. aureus comporte des hélices alpha amphipatiques et hydrophobes dans sa région N-terminale. Cette propriété structurale est retrouvée chez le mastoparan du venin de serpent, l'équinatoxine d'anémone de mer, des peptides de fusion membranaire de certains virus [7, $83,149]$. Cette région servirait à l'ancrage d'un monomère de la toxine dans la bicouche lipidique et à l'association des monomères entre eux. Il est intéressant de rappeler que la toxine $\mathrm{STb}$ d'E. coli comporte également ce motif $\mathrm{N}$-terminal et qu'elle s'insère de façon stable dans la membrane plasmique [17, 143]. De plus, la toxine $\mathrm{STb}$, similairement à la toxine alpha de $S$. aureus, comporte une zone flexible riche en glycine connectant les deux régions $\mathrm{N}$ - et C-terminales. Cependant, le rôle de cette insertion membranaire dans l'action de la toxine STb n'a pas été étudié.

\section{CONCLUSION}

Comprendre l'attachement des toxines bactériennes à la muqueuse intestinale est essentiel pour déterminer comment ces molécules altèrent spécifiquement les fonctions intestinales menant ainsi à une diarrhée. Ces connaissances peuvent même servir de base d'étude pour les interactions impliquées dans l'action des hormones ou dans l'adhésion des cellules de mammifères entre elles. L'étude des mécanismes d'action de certaines toxines a permis leur utilisation comme outils en biologie cellulaire et la mise au point de traitements contre certaines maladies. En effet, plusieurs toxines sont aujourd'hui utilisées comme outils pharmacologiques. Le traitement du strabisme et de la maladie de Parkinson à l'aide de la neurotoxine A de Clostridium botulinum, qui a pour effet de paralyser le système neuromusculaire, en sont des exemples 
probants. Les mécanismes d'action les plus connus sont l'action inhibitrice de la toxine pertusique sur les protéines $\mathrm{G}$, l'activation de l'adénylate cyclase par la toxine cholérique, l'action de la toxine thermostable STa sur la guanylate cyclase et la formation de pore par la toxine alpha de $S$. aureus. La connaissance des structures de complexes toxinerécepteur ouvrent également un important champ d'applications pratiques. L'application la plus prometteuse est la synthèse d'analogues ayant une affinité plus forte que les sites d'attachement naturels, afin d'être utilisés comme inhibiteurs thérapeutiques.

\section{RÉFÉRENCES}

[1] Aktories K., Wegner A., Mechanisms of the cytopathic action of actin-ADP-ribosylating toxins, Mol. Microbiol. 6 (1992) 2905-2908.

[2] Almenoff J.S., Williams S.I., Scheving L.A., Judd A.K., Schoolnik G.K., Ligand-based histochemical localization and capture of cells expressing heat-stable enterotoxin receptors, Mol. Microbiol. 8 (1993) 865-873.

[3] Almenoff J.S., Jurka J., Schoolnik G.K., Induction of heat-stable enterotoxin receptor activity by a human Alu repeat, J. Biol. Chem. 269 (1994) 16610-16617.

[4] Angstrom J., Teneberg S., Karlsson K.A., Delineation and comparison of ganglioside-binding epitopes for the toxins of Vibrio cholerae, Escherichia coli, and Clostridium tetani: evidence for overlapping epitopes, Proc. Natl. Acad. Sci. USA 91 (1994) 11859-11863.

[5] Beachey E.H., Giampapa C.S., Abraham S.N., Bacterial adherence. Adhesin receptor-mediated attachment of pathogenic bacteria to mucosal surfaces, Am. Rev. Resp. Dis. 138 (1988) S45S48.

[6] Bell G.I., Dembo M., Bongrand P., Cell adhesion. Competition between nonspecific repulsion and specific bonding, Biophys. J. 45 (1984) 1051-1064.

[7] Belmonte G., Menestrina G., Pederzolli C., Krizaj I., Gubensek F., Turk T., Macek P., Primary and secondary structure of a pore-forming toxin from the sea anemone, Actinia equina L., and its association with lipid vesicles, Biochim. Biophys. Acta 1192 (1994) 197-204.

[8] Bergdoll M.S., Ileal loop fluid accumulation test for diarrheal toxins, Methods Enzymol. 165 (1988) 306-323.

[9] Bernardi A., Raimondi L., Zuccotto F., Simulation of protein-sugar interactions: a computational model of the complex between gan- glioside GM1 and the heat-labile enterotoxin of Escherichia coli, J. Med. Chem. 40 (1997) 1855-1862.

[10] Bock K., Karlsson K.A., Stromberg N., Teneberg S., Interaction of viruses, bacteria and bacterial toxins with host cell surface glycolipids. Aspects on receptor identification and dissection of binding epitopes, Adv. Exp. Med. Biol. 228 (1988) 153-186.

[11] Boyd B., Tyrrell G., Maloney M., Gyles C., Brunton J., Lingwood C., Alteration of the glycolipid binding specificity of the pig edema toxin from globotetraosyl to globotriaosyl ceramide alters in vivo tissue targetting and results in a verotoxin 1-like disease in pigs, J. Exp. Med. 177 (1993) 1745-1753.

[12] Boyd B., Magnusson G., Zhiuyan Z., Lingwood C.A., Lipid modulation of glycolipid receptor function. Availability of Gal(alpha 1-4)Gal disaccharide for verotoxin binding in natural and synthetic glycolipids, Eur. J. Biochem. 223 (1994) 873-878.

[13] Braden B.C., Dall'Acqua W., Eisenstein E., Fields B.A., Goldbaum F.A., Malchiodi E.L., Mariuzza R.A., Schwarz F.P., Ysern X., Poljak R.J., Protein motion and lock and key complementarity in antigen-antibody reactions, Pharmaceutica Acta Helvetica 69 (1995) 225230.

[14] Buckley J.T., The channel-forming toxin aerolysin, FEMS Med. Microbiol. Immunol. 5 (1992) 13-17.

[15] Calva E., Torres J., Vazquez M., Angeles V., de la Vega H., Ruiz-Palacios G.M., Campylobacter jejuni chromosomal sequences that hybridize to Vibrio cholerae and Escherichia coli LT enterotoxin genes, Gene 75 (1989) 243-251.

[16] Chakraborty T., Schmid A., Notermans S., Benz R., Aerolysin of Aeromonas sobria: evidence for formation of ion-permeable channels and comparison with alpha-toxin of Staphylococcus aureus, Infect. Immun. 58 (1990) 21272132.

[17] Chao K.L., Dreyfus L.A., Interaction of Escherichia coli heat-stable enterotoxin B with cultured human intestinal epithelial cells, Infect. Immun. 65 (1997) 3209-3217.

[18] Cheng S.H., Rich D.P., Marshall J., Gregory R.J., Welsh M.J., Smith A.E., Phosphorylation of the $\mathrm{R}$ domain by cAMP-dependent protein kinase regulates the CFTR chloride channel, Cell 66 (1991) 1027-1036

[19] Chopra A.K., Vo T.N., Houston C.W., Mechanism of action of a cytotonic enterotoxin produced by Aeromonas hydrophila, FEMS Microbiol. Lett. 70 (1992) 15-19.

[20] Clark G.F., Krivan H.C., Wilkins T.D., Smith D.F., Toxin A from Clostridium difficile binds to rabbit erythrocyte glycolipids with terminal Gal alpha 1-3Gal beta 1-4GlcNAc sequences, Arch. Biochem. Biophys. 257 (1987) 217-229. 
[21] Cohen M.B., Guarino A., Shukla R., Giannella R.A., Age-related differences in receptors for Escherichia coli heat-stable enterotoxin in the small and large intestine of children, Gastroenterology 94 (1988) 367-373.

[22] Cohen M.B., Thompson M.R., Giannella R.A., Differences in jejunal and ileal response to $E$. coli enterotoxin: possible mechanisms, Am. J. Physiol. 257 (1989) G118-G123.

[23] Connell T.D., Holmes R.K., Mutational analysis of the ganglioside-binding activity of the type II Escherichia coli heat-labile enterotoxin LT-IIb, Mol. Microbiol. 16 (1995) 21-31.

[24] Cowell S., Aschauer W., Gruber H.J., Nelson K.L., Buckley J.T., The erythrocyte receptor for the channel-forming toxin aerolysin is a novel glycosylphosphatidylinositol-anchored protein, Mol. Microbiol. 25 (1997) 343-350.

[25] Crane J.K., Shanks K.L., Phosphorylation and activation of the intestinal guanylyl cyclase receptor for Escherichia coli heat-stable toxin by protein kinase C, Mol. Cell. Biochem. 165 (1996) 111-120.

[26] Cuatrecasas P., Gangliosides and membrane receptors for cholera toxin, Biochemistry 12 (1973) 3558-3566.

[27] Currie M.G., Fok K.F., Kato J., Moore J.R., Hamra F.K., Duffin K.L., Smith C.E., Guanylin: an endogenous activator of intestinal guanylate cyclase, Proc. Natl. Acad. Sci. USA 89 (1992) 947-951.

[28] De Grandis S., Law H., Brunton J., Gyles C., Lingwood C.A., Globotetraosylceramide is recognized by the pig edema disease toxin, $\mathrm{J}$. Biol. Chem. 264 (1989) 12520-12525.

[29] De Sauvage F.J., Camerato T.R., Goeddel D.V., Primary structure and functional expression of the human receptor for Escherichia coli heatstable enterotoxin, J. Biol. Chem. 266 (1991) 17912-17918.

[30] Dimmock N.J., Review article of initial stages in infection with animal viruses, J. Gen. Virol. 59 (1982) 1-22.

[31] Dreyfus L.A., Harville B., Howard D.E., Shaban R., Beatty D.M., Morris S.J., Calcium influx mediated by the Escherichia coli heat-stable enterotoxin B $\left(\mathrm{ST}_{\mathrm{B}}\right)$, Proc. Natl. Acad. Sci. USA 90 (1993) 3202-3206.

[32] Dubreuil J.D., Escherichia coli STb enterotoxin, Microbiology 143 (1997) 1783-1795.

[33] Dubreuil J.D., Enterotoxigenic Escherichia coli heat-stable toxins, in: Alouf J.E., Freer J.H. (Eds.), The comprehensive sourcebook of bacterial protein toxins, Academic Press, London, 1999, pp. 525-544.

[34] Eidels L., Proia R.L., Hart D.A., Membrane receptors for bacterial toxins, Microbiol. Rev. 47 (1983) 596-620.

[35] Eiklid K., Olsnes S., Interaction of Shigella shigae cytotoxin with receptors on sensitive and insensitive cells, J. Recept. Res. 1 (1980) 199213.

[36] Endo Y., Tsurugi K., Yutsudo T., Takeda Y., Ogasawara T., Igarashi K., Site of action of a Vero toxin (VT2) from Escherichia coli O157:H7 and of Shiga toxin on eukaryotic ribosomes. RNA N-glycosidase activity of the toxins, Eur. J. Biochem. 171 (1988) 45-50.

[37] Fasano A., Cellular microbiology: how enteric pathogens socialize with their intestinal host, Am. Soc. Microbiol. News 63 (1997) 259-265.

[38] Fasano A., Kay B.A., Russell R.G., Maneval D.R. Jr., Levin M.M., Enterotoxin and cytotoxin production by enteroinvasive Escherichia coli, Infect. Immun. 58 (1990) 3717-3723.

[39] Field M., Graf L.H., Laird W.J., Smith P.L., Heat-stable enterotoxin of Escherichia coli: in vitro effects on guanylate cyclase activity, cyclic GMP concentration, and ion transport in small intestine, Proc. Natl. Acad. Sci. USA 75 (1978) 2800-2804.

[40] Fishman P.H., Role of membrane gangliosides in the binding and action of bacterial toxins, $\mathrm{J}$. Membrane Biol. 69 (1982) 85-97.

[41] Fishman P.H., Attikan E.E., Mechanism of action of cholera toxin: effect of receptor density and multivalent binding on activation of adenylate cyclase, J. Membrane Biol. 54 (1980) 51-60.

[42] Forte L.R., Thorne P.K., Eber S.L., Krause W.J., Heeman R.H., Hancis S.H., Corbin J.D., Stimulation of intestinal $\mathrm{Cl}^{-}$transport by heatstable enterotoxin: activation of cAMP-dependent protein kinase by cGMP, Am. J. Physiol. 263 (1992) C607-C615.

[43] Forti S., Menestrina G., Staphylococcal alphatoxin increases the permeability of lipid vesicles by cholesterol- and $\mathrm{pH}$-dependent assembly of oligomeric channels, Eur. J. Biochem. 181 (1989) 767-773.

[44] Frantz J.C., Jaso-Friedman L., Robertson D.C., Binding of Escherichia coli heat-stable enterotoxin to rat intestinal cells and brush border membranes, Infect. Immun. 43 (1984) 622-630.

[45] Fritz G., Schroeder P., Aktories K., Isolation and characterization of a Clostridium botulinum $\mathrm{C} 2$ toxin-resistant cell line: evidence for possible involvement of the cellular C2II receptor in growth regulation, Infect. Immun. 63 (1995) 2334-2340.

[46] Fujii Y., Kondo Y., Okamoto K., Involvement of prostaglandin E2 synthesis in the intestinal secretory action of Escherichia coli heat-stable enterotoxin II, FEMS Microbiol. Lett. 130 (1995) 259-265.

[47] Fujii Y., Nomura T., Yamanaka H., Okamoto $\mathrm{K}$., Involvement of $\mathrm{Ca}(2+)$-calmodulin-dependent protein kinase II in the intestinal secretory action of Escherichia coli heat-stable enterotoxin II, Microbiol. Immunol. 41 (1997) 633636. 
[48] Fukuta S., Magnani J.L., Twiddy E.M., Holmes R.K., Ginsburg V., Comparison of the carbohydrate-binding specificities of cholera toxin and Escherichia coli heat-labile enterotoxins LTh-I, LT-IIa, and LT-IIb, Infect. Immun. 56 (1988) 1748-1753

[49] Galen J.E., Ketley J.M., Fasano A., Richardson S.H., Wasserman S.S., Kaper J.B., Role of Vibrio cholerae neuraminidase in the function of cholera toxin, Infect. Immun. 60 (1992) 406415 .

[50] Ganguly N.K., Kaur T., Mechanism of action of cholera toxin and other toxins, Indian J. Med. Res. 104 (1996) 28-37.

[51] Garland W.J., Buckley J.T., The cytolytic toxin aerolysin must aggregate to disrupt erythrocytes, and aggregation is stimulated by human glycophorin, Infect. Immun. 56 (1988) 12491253.

[52] Gemmell C.G., Comparative study of the nature and biological activities of bacterial enterotoxins, J. Med. Microbiol. 17 (1984) 217-235.

[53] Giannella R.A., Luttrell M., Thompson M., Binding of Escherichia coli heat-stable enterotoxin to receptors on rat intestinal cells, Am. J. Physiol. 245 (1983) G492-G498.

[54] Greenberg R.N., Hill M., Crytzer J., Krause W.J., Eber S.L., Hamra F.K., Forte L.R., Comparison of effects of uroguanylin, guanylin, and Escherichia coli heat-stable enterotoxin STa in mouse intestine and kidney: evidence that uroguanylin is an intestinal natriuretic hormone, J. Invest. Med. 45 (1997) 276-282.

[55] Griffiths S.L., Critchley D.R., Characterization of the binding sites for Escherichia coli heatlabile toxin type I in intestinal brush borders, Biochim. Biophys. Acta 1075 (1991) 154-161.

[56] Griffiths S.L., Finkelstein R.A., Critchley D.R., Characterization of the receptor for cholera toxin and Escherichia coli heat-labile toxin in rabbit intestinal brush borders, Biochem. J. 238 (1986) 313-322.

[57] Guarino A., Cohen M., Thompson M., Dharmsathaphorn K., Giannella R., T84 cell receptor binding and guanyl cyclase activation by Escherichia coli heat-stable toxin, Am. J. Physiol. 253 (1987) G775-G780.

[58] Guarino A., Cohen M.B., Overmann G., Thompson M.R., Giannella R.A., Binding of $E$. coli heat-stable enterotoxin to rat intestinal brush borders and to basolateral membranes, Dig. Dis. Sci. 32 (1987) 1017-1026.

[59] Gyles C.L., Escherichia coli cytotoxins and enterotoxins, Can. J. Microbiol. 38 (1992) 734746 .

[60] Hanna P.C., McClane B.A., A recombinant Cterminal toxin fragment provides evidence that membrane insertion is important for Clostridium perfringens enterotoxin cytoxicity, Mol. Microbiol. 5 (1991) 225-230.
[61] Harville B.A., Dreyfus L.A., Release of serotonin from RBL-2H3 cells by the Escherichia coli peptide toxin STb, Peptides 17 (1996) 363366.

[62] Hildebrand A., Pohl M., Bhakdi S., Staphylococcus aureus alpha-toxin. Dual mechanism of binding to target cells, J. Biol. Chem. 266 (1991) 17195-17200.

[63] Hippenstiel S., Tannert-Otto S., Vollrath N., Krull M., Just I., Aktories K., von Eichel-Streiber C., Suttorp N., Glucosylation of small GTPbinding Rho proteins disrupts endothelial barrier function, Am. J. Physiol. 272 (1997) L38-L43.

[64a] Hirayama T., Wada A., Iwata N., Takasaki S., Shimonishi Y., Takeda Y., Glycoprotein receptors for a heat-stable enterotoxin (STh) produced by enterotoxigenic Escherichia coli, Infect. Immun. 60 (1992) 4213-4220.

[64b] Hirst T.R., Cholera toxin and Escherichia coli enterotoxin, in: Alouf J.E., Freer J.H. (Eds.), The Comprehensive Sourcebook of Bacterial Protein Toxins, Academic Press, London, 1999, pp. 104-129.

[65] Holmgren J., Lönnroth I., Mansson J.-E., Svennerholm L., Interaction of cholera toxin and membrane GM1 ganglioside of the small intestine, Proc. Natl. Acad. Sci. USA 72 (1975) 2520-2524.

[66] Holmgren J., Fredman P., Lindblad M., Svennerholm A.M., Svennerholm L., Rabbit intestinal glycoprotein receptor for Escherichia coli heat-labile enterotoxin lacking affinity for cholera toxin, Infect. Immun. 38 (1982) 424433.

[67] Holmgren J., Lindblad M., Fredman P., Svennerholm L., Myrvold H., Comparison of receptors for cholera and Escherichia coli enterotoxins in human intestine, Gastroenterology 89 (1985) 27-35

[68] Huott P.A., Liu W., McRoberts J.A., Gianella R.A., Mechanism of action of Escherichia coli heat-stable enterotoxin in a human colonic cell line, J. Clin. Invest. 82 (1988) 514-523.

[69] IUPAC-IUB Commission on Biochemical Nomenclature C.B.N., The nomenclature of lipids, Biochem. J. 171 (1978) 21-35.

[70] IUPAC-IUB Joint Commission on Biochemical Nomenclature J.C.B.N., Nomenclature of glycoproteins, glycopeptides and peptidoglycans. Recommendations 1985, Eur. J. Biochem. 159 (1986) 1-6.

[71] Jacewicz M., Clausen H., Nudelman E., Donohue-Rolfe A., Keusch G.T., Pathogenesis of shigella diarrhea. XI. Isolation of a Shigella toxin-binding glycolipid from rabbit jejunum and HeLa cells and its identification as globotriaosylceramide, J. Exp. Med. 163 (1986) 1391-1404.

[72] Jacewicz M., Feldman H.A., Donohue-Rolfe A., Balasubramanian K.A., Keusch G.T., Pathogenesis of Shigella diarrhea. XIV. Analysis of 
shiga toxin receptors on cloned HeLa cells, J. Infect. Dis. 159 (1989) 881-889.

173] Janin J., Chothia C., The structure of proteinprotein recognition sites, J. Biol. Chem. 265 (1990) 16027-16030.

[74] Jemal C., Haddad J.E., Begum D., Jackson M.P., Analysis of Shiga toxin subunit association by using hybrid A polypeptides and sitespecific mutagenesis, J. Bacteriol. 177 (1995) 3128-3132.

[75] Jones G.W., Isaacson R.E., Proteinaceous bacterial adhesins and their receptors, Crit. Rev. Microbiol. 10 (1983) 229-260.

[76] Just I., Wilm M., Selzer J., Rex G., von EichelStreiber C., Mann M., Aktories K., The enterotoxin from Clostridium difficile (ToxA) monoglucosylates the Rho proteins, J. Biol. Chem. 270 (1995) 13932-13936.

[77] Kabat E.A., Antibody complementarity and antibody structure, J. Immunol. 141 (1988) S25S36.

[78] Kandel G., Donohue-Rolfe A., Donowitz M., Keusch G.T., Pathogenesis of Shigella diarrhea. XVI. Selective targetting of Shiga toxin to villus cells of rabbit jejunum explains the effect of the toxin on intestinal electrolyte transport, J. Clin. Invest. 84 (1989) 1509-1517.

[79] Karlsson K.A., Animal glycolipids as attachment sites for microbes, Chem. Phys. Lipids 42 (1986) 153-172.

[80] Karlsson K.A., Ångstrom J., Bergstrom J., Lanne B., Microbial interaction with animal cell surface carbohydrates, Acta Pathol. Microbiol. Immunol. Scand. - Supp. 100 (1992) 71-83.

[81] Katahira J., Inoue N., Horiguchi Y., Matsuda M., Sugimoto N., Molecular cloning and functional characterization of the receptor for Clostridium perfringens enterotoxin, J. Cell Biol. 136 (1997) 1239-1247

[82] Katahira J., Sugiyama H., Inoue N., Horiguchi Y., Matsuda M., Sugimoto N., Clostridium perfringens enterotoxin utilizes two structurally related membrane proteins as functional receptors in vivo, J. Biol. Chem. 272 (1997) 2665226658.

[83] Katsu T., Kuroko M., Morikawa T., Sanchika K., Yamanaka H., Shinoda S., Fujita Y., Interaction of wasp venom mastoparan with biomembranes, Biochim. Biophys. Acta 1027 (1990) 185-190.

[84] Keusch G.T., Donowitz M., Pathophysiological mechanisms of diarrhoeal diseases: diverse aetiologies and common mechanisms, Scand. J. Gastroenterol. - Supp. 84 (1983) 33-43.

[85] Keusch, G.T., Jacewicz, M., Pathogenesis of Shigella diarrhea. VII. Evidence for a cell membrane toxin receptor involving beta 1 leads to 4linked N-acetyl-D-glucosamine oligomers, J. Exp. Med. 146 (1977) 535-546.
86] Keusch G.T., Jacewicz M., Donohue-Rolfe A., Pathogenesis of Shigella diarrhea: evidence for an $\mathrm{N}$-linked glycoprotein shigella toxin receptor and receptor modulation by $\beta$-galactosidase, J. Infect. Dis. 153 (1986) 238-248.

[87] Keusch G.T., Jacewicz M., Acheson D.W.K., Donohue-Rolfe A., Globotriaosylceramide, $\mathrm{Gb} 3$, is an alternative functional receptor for shiga-like toxin 2e, Infect. Immun. 63 (1995) 1138-1141.

[88] Khuruna S., Ganguly N.K., Khullar M., Panigrahi D., Walia B.N., Studies on the mechanism of Salmonella typhimurium enterotoxininduced diarrhoea, Biochim. Biophys. Acta 1097 (1991) 171-176.

[89] Klipstein F.A., Engert R.F., Immunological relationship of the B subunits of Campylobacter jejuni and Escherichia coli heat-labile enterotoxins, Infect. Immun. 48 (1985) 629-633.

[90] Krause W.J., Cullingford R.H., Freeman R.H., Eber S.L., Richardson K.C., Fok K.F., Currie M.G., Forte L.R.., Distribution of heat-stable enterotoxin on $\mathrm{Cl}^{-}$secretion in human gut, J. Anat. 184 (1994) 407-417.

[91] Krivan H.C., Clark G.F., Smith D.F., Wilkins T.D., Cell surface binding site for Clostridium difficile enterotoxin: evidence for a glycoconjugate containing the sequence Gal alpha 13 Gal beta 1-4GlcNAc, Infect. Immun. 53 (1986) 573-581.

[92] Kuhn M., Adermann K., Jahne J., Forssmann W.G., Rechkemmer G., Segmental differences in the effects of guanylin and Escherichia coli heat-stable enterotoxin on $\mathrm{Cl}^{-}$secretion in human gut, J. Physiol. 479 (1994) 433-440.

[93] Levis M.J., Bourne H.R., Activation of the alpha subunit of Gs in intact cells alters its abundance, rate of degradation, and membrane avidity, $\mathrm{J}$. Cell Biol. 119 (1992) 1297-1307.

[94] Lindberg A.A., Brown J.E., Stromberg N., Westling-Ryd M., Schultz J.E., Karlsson K.A., Identification of the carbohydrate receptor for Shiga toxin produced by Shigella dysenteriae type 1, J. Biol. Chem. 262 (1987) 1779-1785.

[95] Lingwood C.A., Law H., Richardson S., Petric M., Brunton J.L., De Grandis S., Karmali M. Glycolipid binding of purified and recombinant Escherichia coli produced verotoxin in vitro, J. Biol. Chem. 262 (1987) 8834-8839.

[96] Lucas F., Corthier G., Les récepteurs aux entérotoxines bactériennes, Ann. Rech. Vét. 22 (1991) 127-145

[97] Lucas F., Popoff M., Corthier G., Les entérotoxines bactériennes: structure, mode d'action, Ann. Rech. Vét. 22 (1991) 147-162.

[98] Magnani J.L., Smith D.F., Ginsburg V., Detection of gangliosides that bind cholera toxin: direct binding of ${ }^{125}$ I-labeled to thin-layer chromatograms, Anal. Biochem. 109 (1980) 399402 . 
99] Mainil J., Shiga/verotoxins and shiga/verotoxigenic Escherichia coli in animals, Vet. Res. 30 (1999) 235-257.

[100] Mann E.A., Cohen M.B., Giannella R.A., Comparison of receptors for Escherichia coli heatstable enterotoxin: novel receptor present in IEC-6 cells, Am. J. Physiol. 264 (1993) G172G178.

[101] Matsuda M., Sugimoto N., Calcium-independent and dependent steps in action of Clostridium perfringens enterotoxin on HeLa and Vero cells, Biochem. Biophys. Res. Commun. 91 (1979) 629-636

[102] McClane B.A., Wnek A.P., Studies of Clostridium perfringens enterotoxin action at different temperatures demonstrate a correlation between complex formation and cytotoxicity, Infect. Immun. 58 (1990) 3109-3115.

[103a] McClane B.A., Wnek A.P., Hulkower K.I., Hanna P.C., Divalent cation involvement in the action of Clostridium perfringens type A enterotoxin. Early events in enterotoxin action are divalent cation-independent, J. Biol. Chem. 263 (1988) 2423-2435.

[103b] Menestrina G., Ferreras M., Alpha-toxin (Staphylococcus aureus), in: Rappuoli R., Montecucco C. (Eds.), Guidebook to protein toxins and their use in cell biology, Sambrook and Tooze publication, Oxford University Press, Great Britain, 1997, pp. 10-13.

[104] Menestrina G., Bashford C.L., Pasternak C.A., Pore-forming toxins: experiments with $S$. aureus alpha-toxin, $C$. perfringens theta-toxin and $E$. coli haemolysin in lipid bilayers, liposomes and intact cells, Toxicon 28 (1990) 477-491.

[105] Menestrina G., Schiavo G., Montecucco C., Molecular mechanisms of action of bacterial protein toxins, Mol. Aspects Med. 15 (1994) 79-193.

[106] Mezoff A.G., Giannella R.A., Eade M.N., Cohen M.B., Escherichia coli enterotoxin (STa) binds to receptors stimulates guanyl cyclase, and impairs absorption in rat colon, Gastroenterology 102 (1992) 816-822.

[107] Miller-Podraza H., Bradley R.M., Fishman P.H., Biosynthesis and localization of gangliosides in cultured cells, Biochemistry 21 (1982) 32603265 .

[108] Mobassaleh M., Donohue-Rolfe A., Jacewicz M., Grand R.J., Keusch G.T., Pathogenesis of shigella diarrhea: evidence for a developmentally regulated glycolipid receptor for shigella toxin involved in the fluid secretory response of rabbit small intestine, J. Infect. Dis. 157 (1988) 1023-1031.

[109] Mobassaleh M., Gross S.K., McCluer R.H., Donohue-Rolfe A., Keusch G.T., Quantitation of the rabbit intestinal glycolipid receptor for Shiga toxin. Further evidence for the developmental regulation of globotriaosylceramide in microvillus membranes, Gastroenterology 97 (1989) 384-391.

[110] Moniatte M., van der Goot F.G., Buckley J.T., Pattus F., van Dorsselaer A., Characterization of the heptameric pore-forming complex of the Aeromonas toxin aerolysin using MALDI-TOF mass spectrometry, FEBS Lett. 384 (1996) 269272.

[111] Moss J., Fishman P.H., Manganiello V.C., Vaughan M., Brady R.O., Functional incorporation of ganglioside into intact cells: induction of choleragen responsiveness, Proc. Natl. Acad. Sci. USA 73 (1976) 1034-1037.

[112] Moss J., Garrison S., Fishman P.H., Richardson S.H., Gangliosides sensitize unresponsive fibroblasts to Escherichia coli heat-labile enterotoxin, J. Clin. Invest. 64 (1979) 381-384.

[113] Nagy B., Fekete P.Z., Enterotoxigenic Escherichia coli (ETEC) in farm animals, Vet. Res. 30 (1999) 259-284.

[114] Nelson K.L., Raja S.M., Buckley J.T., The glycosylphosphatidylinositol-anchored surface glycoprotein Thy- 1 is a receptor for the channelforming toxin aerolysin, J. Biol. Chem. 272 (1997) 12170-12174.

[115] O 'Brien A.D., Holmes R.K., Shiga and Shigalike toxins, Microbiol. Rev. 51 (1987) 206-220.

[116] Orlandi P.A., Critchley D.R., Fishman P.H., The heat-labile enterotoxin of Escherichia coli binds to polylactosaminoglycan-containing receptors in $\mathrm{CaCo}-2$ human intestinal epithelial cells, Biochemistry 33 (1994) 12886-12895.

[117] Padlan E.A., Kabat E.A., Modeling of antibody combining sites, Methods Enzymol. 203 (1991) 3-21.

[118] Parkinson S.J., Alekseev A.E., Gomez L.A., Wagner F., Terzic A., Waldman S.A., Interruption of Escherichia coli heat-stable enterotoxin-induced guanylyl cyclase signaling and associated chloride current in human intestinal cells by 2-chloroadenosine, J. Biol. Chem. 272 (1997) 754-758.

[119] Paulson J.C., Glycoproteins: what are the sugar chains for?, Trends Biochem. Sci. 14 (1989) 272-276.

[120] Pothoulakis C., LaMont J.T., Eglow R., Gao N., Rubins J.B., Theoharides T.C., Dickey B.F., Characterization of rabbit ileal receptors for Clostridium difficile toxin A. Evidence for a receptor-coupled $\mathrm{G}$ protein, J. Clin. Invest. 88 (1991) 119-225.

[121] Pothoulakis C., Gilbert R.J., Cladaras C., Castagliuolo I., Semenza G., Hitti Y., Montcrief J.S., Linevsky J., Kelly C.P., Nikulasson S., Desai H.P., Wilkins T.D., LaMont J.T., Rabbit sucrase-isomaltase contains a functional intestinal receptor for Clostridium difficile toxin A, J. Clin. Invest. 98 (1996) 641-649.

[122] Raimondi F., Kao J.P., Kaper J.B., Guandalini S., Fasano A., Calcium-dependent intestinal chloride secretion by Vibrio parahaemolyticus 
thermostable direct hemolysin in a rabbit model, Gastroenterology 109 (1995) 381-386.

[123] Reisbig R., Olsnes S., Eiklid K., The cytotoxic activity of Shigella toxin. Evidence for catalytic inactivation of the $60 \mathrm{~S}$ ribosomal subunit, J. Biol. Chem. 256 (1981) 8739-8744.

[124] Robins-Browne R.M., Takeda T., Fasano A., Bordun A.M., Dohi S., Kasuga H., Fang G., Prado V., Guerrant R.L., et al., Assessment of enterotoxin production by Yersinia enterocolitica and identification of a novel heat-stable enterotoxin produced by a noninvasive $Y$. enterocolitica strain isolated from clinical material, Infect. Immun. 61 (1993) 764-767.

[125] Rousset E., Harel J., Dubreuil J.D., Binding characteristics of Escherichia coli enterotoxin b $(\mathrm{STb})$ to the pig jejunum and partial characterization of the molecule involved, Microbial Pathogen. 24 (1998) 277-288.

[126] Rousset E., Harel J., Dubreuil J.D., Sulfatide from the pig jejunum brush border epithelial cell surface is involved in binding of Escherichia coli enterotoxin b, Infect. Immun. 66 (1998) 5650-5658.

[127] Samuel J.E., Perera L.P., Ward S., O'Brien A.D., Ginsburg V., Krivan H.C., Comparison of the glycolipid receptor specificities of Shigalike toxin type II and Shiga-like toxin type II variants, Infect. Immun. 58 (1990) 611-618.

[128] Sandvig K., Olsnes S., Brown J.E., Petersen O.W., van Deurs B., Endocytosis from coated pits of Shiga toxin: a glycolipid-binding protein from Shigella dysenteriae type 1, J. Cell Biol. 108 (1989) 1331-1343.

[129] Sauerborn M., Leukel P., von Eichel-Streiber C., The C-terminal ligand-binding domain of Clostridium difficile toxin A (TcdA) abrogates TcdA-specific binding to cells and prevents mouse lethality, FEMS Microbiol. Lett. 155 (1997) 45-54

[130] Savarino S.J., Fasano A., Watson J., Martin B.M., Levine M.M., Guandalini S., Guerry P., Enteroaggregative Escherichia coli heat-stable enterotoxin 1 represents another subfamily of $E$. coli heat-stable toxin, Proc. Natl. Acad. Sci. USA 90 (1993) 3093-3097.

[131] Schultz S., Green C.K., Yuen P.S., Garbers D.L., Guanylyl cyclase is a heat-stable enterotoxin receptor, Cell 63 (1990) 941-948.

[132] Sears C.L., Kaper J.B., Enteric bacterial toxins: mechanisms of action and linkage to intestinal secretion, Microbiol. Rev. 60 (1996) 167-215.

[133] Sherman S., Klein E., McClane B.A., Clostridium perfringens type $\mathrm{A}$ enterotoxin induces tissue damage and fluid accumulation in rabbit ileum, J. Diarrhoeal Dis. Res. 12 (1994) 200207.

[134] Shida K., Takamizawa K., Nagaoka M., Tsuji T., Osawa T., Escherichia coli heat-labile enterotoxin binds to glycosylated proteins with lac- tose by amino carbonyl reaction, Microbiol. Immunol. 38 (1994) 273-279.

[135] Sixma T.K., Pronk S.E., Kalk K.H., Wartna E.S., van Zanten B.A., Witholt B., Hol W.G., Crystal structure of a cholera toxin-related heatlabile enterotoxin from E. coli, Nature 351 (1991) 371-377.

[136] Sixma T.K., Aguirre A., Terwisscha van Scheltinga A.C., Wartna E.S., Kalk K.H., Hol W.G., Heat-labile enterotoxin crystal forms with variable A/B5 orientation. Analysis of conformational flexibility, FEBS Lett. 305 (1992) 8185.

[137] Sixma T.K., Kalk K.H., van Zanten B.A., Dauter Z., Kingma J., Witholt B., Hol W.G., Refined structure of Escherichia coli heat-labile enterotoxin, a close relative of cholera toxin, J. Mol. Biol. 230 (1993) 890-918.

[138] Sixma T.K., Stein P.E., Hol W.G., Read R.J., Comparison of the B-pentamers of heat-labile enterotoxin and verotoxin-1: two structures with remarkable similarity and dissimilarity, Biochemistry 32 (1993) 191-198.

[139] Smith J.A., Cooke D.L., Hyde S., Borriello S.P., Long R.G., Clostridium difficile toxin A binding to human intestinal epithelial cells, J. Med. Microbiol. 46 (1997) 953-958.

[140] Spiegel S., Schlessinger J., Fishman P.H., Incorporation of fluorescent gangliosides into human fibroblasts: mobility, fate, and interaction with fibronectin, J. Cell Biol. 99 (1984) 699-704.

[141] Stein P.E., Boodhoo A., Tyrrell G.J., Brunton J.L., Read R.J., Crystal structure of the cellbinding B oligomer of verotoxin-1 from E. coli, Nature 355 (1992) 748-750.

[142] Sugimoto N., Takagi M., Ozutsumi K., Harada S., Matsuda M., Enterotoxin of Clostridium perfringens type A forms ion-permeable channels in a lipid bilayer membrane, Biochem. Biophys. Res. Commun. 156 (1988) 551-556.

[143] Sukumar M., Rizo J., Wall M., Dreyfus L.A., Kupersztoch Y.M., Gierasch L.M., The structure of Escherichia coli heat-stable enterotoxin b by nuclear magnetic resonance and circular dichroism, Protein Sci. 4 (1995) 1718-1729.

[144] Takeda Y., Enterohaemorragic Escherichia coli, World Health Statistics Quarterly 50 (1997) 7480.

[145] Takeda T., Yoshino K.-I., Ramamurthy T., Nair G.B., Heat-stable enterotoxins of Vibrio and Yersinia species, in: Alouf J.E., Freer J.H. (Eds.), The comprehensive sourcebook of bacterial protein toxins, Academic Press, London, 1999 , pp. $545-556$.

[146a] Tang G.Q., Iida T., Yamamoto K., Honda T., A mutant toxin of Vibrio parahaemolyticus thermostable direct hemolysin which has lost hemolytic activity but retains ability to bind to erythrocytes, Infect. Immun. 62 (1994) 3299-3304.

[146b] Thelestam M., Chaves-Olarte E., Moos M., von Eichel-Streiber C., Clostridial toxins acting on 
the cytoskeleton, in: Alouf J.E., Freer J.H. (Eds.), Comprehensive Sourcebook of Bacterial Protein Toxins, 1999, pp. 147-173.

[147] Teneberg S., Lonnroth I., Torres Lopez J.F., Galili U., Halvarsson M.O., Angström J., Karlsson K.A., Molecular mimicry in the recognition of glycosphingolipids by $\mathrm{Gal}$ alpha $3 \mathrm{Gal}$ beta 4 GlcNAc beta-binding Clostridium difficile toxin $\mathrm{A}$, human natural anti alpha-galactosyl IgG and the monoclonal antibody Gal-13: characterization of a binding-active human glycosphingolipid, non-identical with the animal receptor, Glycobiology 6 (1996) 599-609.

[148] Tesh V.L., O'Brien A.D., The pathogenic mechanisms of Shiga toxin and the Shiga-like toxins, Mol. Microbiol. 5 (1991) 1817-1822.

[149] Thiaudiere E., Siffert O., Talbot J.C., Bolard J., Alouf J.E., Dufourcq J., The amphiphilic alpha-helix concept. Consequences on the structure of staphylococcal delta-toxin in solution and bound to lipids, Eur. J. Biochem. 195 (1991) 203-213.

[150] Thurin J., Binding sites of monoclonal anti-carbohydrate antibodies, Curr. Topics Microbiol. Immunol. 139 (1988) 59-79.

[151] Tomasi M., Montecucco C., Lipid insertion of cholera toxin after binding to GM1-containing liposomes, J. Biol. Chem. 256 (1981) 1117711181.

[152] Tucker K.D., Wilkins T.D., Toxin A of Clostridium difficile binds to the human carbohydrate antigens I, X, and Y, Infect. Immun. 59 (1991) 73-78.

[153] Tucker K.D., Carrig P.E., Wilkins T.D., Toxin A of Clostridium difficile is a potent cytotoxin, $\mathrm{J}$. Clin. Microbiol. 28 (1990) 869-871.

[154] Vaandrager A.B., Schulz S., De Jonge H.R., Garbers D.L., Guanylyl cyclase is an N-linked glycoprotein receptor that accounts for multiple heat-stable enterotoxin-binding proteins in the intestine, J. Biol. Chem. 268 (1993) 2174-2179.

[155] van den Akker, F., Sarfaty, S., Twiddy, E.M., Connell, T.D., Holmes, R.K., Hol, W.G., Crystal structure of a new heat-labile enterotoxin, LT-IIb, Structure 4 (1996) 665-678.

[156] van Heyningen W.E., Carpenter C.C.J., Pierce N.F., Greenough III W.B., Induction of cholera toxin by ganglioside., J. Infect. Dis. 124 (1971) 415-418.
[157] Wada A., Hirayama T., Kitaura H., Fujisawa J., Hasegawa M., Hidaka Y., Shimonishi Y., Identification of ligand recognition sites in heatstable enterotoxin receptor, membrane-associated guanylyl cyclase $\mathrm{C}$ by site-directed mutational analysis, Infect. Immun. 64 (1996) 5144-5150.

[158] Waddell T., Head S., Petric M., Cohen A., Lingwood C., Globotriosyl ceramide is specifically recognized by the Escherichia coli verocytotoxin 2, Biochem. Biophys. Res. Commun. 152 (1988) 674-679.

[159] Waddell T., Cohen A., Lingwood C., Reconstitution of verotoxin sensitivity in receptor-deficient cell lines using the receptor glycolipid globotriosylceramide, Proc. Natl. Acad. Sci. USA 87 (1990) 7898-7901.

[160] Weikel C.S., Sando J.J., Guerrant R.L., Stimulation of porcine jejunal ion secretion in vivo by protein kinase-C activators, J. Clin. Invest. 76 (1985) 2430-2435.

[161] Wilmsen H.U., Leonard K.R., Tichelaar W., Buckley J.T., Pattus F., The aerolysin membrane channel is formed by heptamerization of the monomer, EMBO J. 11 (1992) 2457-2463.

[162] Wnek A.P., McClane B.A., Comparison of receptors for Clostridium perfringens type A and cholera enterotoxins in isolated rabbit intestinal brush border membranes, Microb. Pathog. 1 (1986) 89-100.

[163] Wnek A.P., McClane B.A., Preliminary evidence that Clostridium perfringens type A enterotoxin is present in a $160,000-\mathrm{Mr}$ complex in mammalian membranes, Infect. Immun. 57 (1989) 574-581.

[164] Yamamoto T., Wakisaka N., Sato F., Kato A., Comparison of the nucleotide sequence of enteroaggregative Escherichia coli heat-stable enterotoxin 1 genes among diarrhea-associated Escherichia coli, FEMS Microbiol. Lett. 147 (1997) 89-95.

[165] Yoh M., Morinaga N., Noda M., Honda T., The binding of Vibrio parahaemolyticus ${ }^{125}$ I-labeled thermostable direct hemolysin to erythrocytes, Toxicon 33 (1995) 651-657.

[166] Zemelman B.V., Chu S.H., Walker W.A., Host response to Escherichia coli heat-labile enterotoxin via two microvillus membrane receptors in the rat intestine, Infect. Immun. 57 (1989) 2947-2952. 